\title{
INTRODUCCION
}

La bibliografía de la obra de Mario Benedetti y del comentario crítico sobre el trabajo suyo comenzó hace tres años como un paso preparativo a un estudio sobre algunos escritores del grupo "Marcha".

Tuve la oportunidad de conversar personalmente con el señor Benedetti en abril 1977 y en diciembre 1979 en La Habana, Cuba. A sugerencia de él y con el permiso del editor Ambrosio Fornet, he incluido datos bibliográficos del texto Recopilación de textos sobre Mario Benedetti (Casa de las Américas, 1976).

Mi deseo es que este trabajo facilite y motive nuevos estudios sobre este escritor latinoamericano, cuya significativa obra y trayectoria personal muestran claramente la relación entre las ideologías contemporáneas y el arte literario.

Deseo expresar mi reconocimiento a la Universidad de Saskatchewan por el apoyo prestado en los viajes de 1978, 1979, y 1980 que me dieron la oportunidad de usar los recursos bibliográficos de la Universidad Stanford y del Instituto Hoover en Stanford, California; del Centro para Estudios Latinoamericanos, Gainesville, Florida; de la Universidad Yale, New Haven, Connecticut; de la Universidad de Wisconsin, Madison, Wisconsin; y de la Universidad de Pittsburgh, Pittsburgh, Pennsylvania.

Así también agradezco la ayuda de los que en una forma u otra contribuyeron a la realización de este proyecto, pero en especial a la señora Janet McLean por sus consejos técnicos, al señor Eudoxio Paredes-Ruiz por la lectura y correcciones del manuscrito y a la señora Julieta Lazo Acoose por la paciencia en el trabajo mecanográfico, cuyo proceso exigió cambios continuos.

Merece mención la espontánea contribución de mis colegas, la Dra. Lois Kemp y la Dra. Eileen Zeitz al proveerme de datos sobre artículos y entradas bibliográficas aparecidas en Europa.

No debo terminar esta introducción sin agradecer una vez más la gentil cooperación recibida para este trabajo del mismo escritor, Mario Benedetti.

Pese a la atención puesta durante la realización de esta bibliografía, no es comprensiva ni perfecta debido a circunstancias de tiempo y recursos disponibles. Espero continuar en la faena y en el futuro añadir información para compensar las deficiencias.

Freda Pérez Beberfall

Universidad de Saskatchewan

Saskatoon, Saskatchewan

Canada 


\section{BIBLIOGRAFIA DE Y SOBRE MARIO BENEDETTI}

\section{OBRAS DE MARIO BENEDETTI}

[Por orden cronológico de la publicación]

\section{A. POESIA}

La vispera indeleble. [Ed. de autor]. Montevideo: Imprenta Prometeo, 1945.

Sólo mientras tanto. Montevideo: Número, 1950. [Obra incluida a partir de 1963 en las sucesivas ediciones de Inventario ]

Poemas de la oficina. 1ra. ed. Montevideo: Número, 1956. 2da. ed. Buenos Aires: Editorial Ñandú, 1958; 3ra. ed. Montevideo: Editores Reunidos y Arca, 1969. [Con título Poemas de la oficina y otros expedientes ]

Poemas del hoyporhoy. Montevideo: Alfa, 1961. [Obra incluida a partir de 1963 en las sucesivas ediciones de Inventario ]

Inventario. 1ra. ed. Colección Carabela. Montevideo: Alfa, 1963; 2a. ed. Montevideo: Alfa, 1965; 3ra. ed. [Aumentada]. Montevideo: Alfa, 1967; 4a. ed. [Aumentada]. Montevideo: Alfa, 1970; 5a. ed. [Aumentada]. Buenos Aires: Alfa Argentina, 1974; 6a. ed. México, D.F.: Nueva Imagen/Alfa Argentina, septiembre 1978; 7a. ed. México, D.F.: Nueva Imagen/Alfa Argentina, diciembre 1978; 8a. ed. [No autorizada]. Caracas: Editorial Lego, 1978; 9a. ed. [Aumentada]. México, D.F.: Nueva Imagen, 1979; 10a. ed. México, D.F.: Nueva Imagen, 1980; 11a. ed. Madrid: Visor, 1980.

Contra los puentes levadizos. Colección poesía hoy: 23. Montevideo: Alfa, 1966. [Obra incluida a partir de 1966 en las sucesivas ediciones de Inventario ]

Antología natural. Montevideo: Alfa, 1967.

"Corazón Coraza". En: Holzcan, Carlos Guillermo. Comp. Antología de la poesía erótica. Buenos Aires: Globo Rojo, 1967, pp. 29-30.

A ras de sueño. Montevideo: Alfa, 1967. [Obra incluida a partir de 1967 en las sucesivas ediciones de Inventario]. 
“Señas del Che". En: Fierro, Enrique. Comp. Antología de la poesía rebelde hispanoamericana. Montevideo: Banda Oriental, 1967, p. 81.

“Señas del Che". Revista Casa de las Américas (La Habana), № 44, 1967, p. 90.

"Señor de los tristes". Revista Casa de las Américas (La Habana), No. 42, 1967 , p. 78.

"Angelus". En: Fierro, Enrique. Comp. La poesía del 45. Montevideo: Centro Editor de América Latina, 1968, p. 7.

“Angelus". En: Altamirano Carlos. Comp. Poesía social del siglo $X X$ : España e Hispanoamérica. Buenos Aires: Centro Editor de América Latina, 1971, p. 65.

"A la izquierda del roble". En: Fierro, Enrique. Comp. La poesía del 45. Montevideo: Centro Editor de América Latina, 1968, pp. 9-13.

“Adelante". En: Fierro, Enrique. Comp. La poesía del 45. Montevideo: Centro Editor de América Latina, 1968, pp. 15-16.

“Arte Poética”. En: Fierro, Enrique. Comp. La poesía del 45. Montevideo:

Centro Editor de América Latina, 1968, p. 15.

"Ausencia". En: Fierro, Enrique. Comp. La poesia del 45. Montevideo:

Centro Editor de América Latina, 1968, pp. 7-8.

"Habanera". En: Fierro, Enrique. Comp. La poesía del 45. Montevideo: Centro Editor de la América Latina, 1968, pp. 16-17.

“Pobre Dios". En: Fierro, Enrique. Comp. La poesía del 45. Montevideo: Centro Editor de América Latina, 1968, pp. 8-9.

"Socorro y nadie". En: Fierro, Enrique. Comp. La poesia del 45. Montevideo: Centro Editor de la América Latina, 1968, pp. 13-14.

"La trampa". En: Fierro, Enrique. Comp. La poesía del 45. Montevideo: Centro Editor de América Latina, 1968, pp. 14-15.

"Poemas de la oficina y otros expedientes". En: Enciclopedia uruguaya (Montevideo), No. 6, 1969, pp. 99-120.

"Quemar las naves". En: Altamirano, Carlos. Comp. Poesía social del siglo $X X$ : España e Hispanoamérica. Buenos Aires: Centro Editor de América Latina, 1971, p. 67.

"Todos conspiramos". En: Altamirano, Carlos. Comp. Poesía social del siglo XX: España e Hispanoamérica. Buenos Aires: Centro Editor de América Latina, 1971, p. 67. 
"Tres odas provisiorias". Casa de las Américas (La Habana), Vol. 13, No. 74, septiembre-octubre 1972, pp. 68-70.

“Cosas de uno". En: Barros, Daniel. Comp. Antología básica contemporánea de la poesía latinoamericana. Buenos Aires: Ediciones de la Flor, 1973, pp. 234-235.

"Esta ciudad es de mentira". En: Barros, Daniel. Comp. Antología básica contemporánea de la poesía latinoamericana. Buenos Aires: Ediciones de la Flor, 1973, pp. 233-234.

"Esta ciudad es de mentira". En: Baciu, Stefan. Comp. Antología de la poesía latinoamericana, 1950-1970. Vol. 2. Albany: State University Press of New York, 1974, pp. 1118-1119.

"Militancia". En: "Uruguay y ¿Ahora Qué?" [Número especial]. Cuadernos de Crisis (Buenos Aires), No. 4, 1973?, pp. 93-94.

"Kindergarten". En: Baciu, Stefan. Comp. Antología de la poesía latinoamericana, 1950-1970. Vol 2. Albany: State University Press of New York, 1974, pp. 1115-1117.

"Vuelo 202". En: Baciu, Stefan. Comp. Antología de la poesia latinoamericana, 1950-1970. Vol. 2. Albany: State University of New York, 1974, p. 1113.

Poemas de otros. 1ra. ed. Buenos Aires: Alfa Argentina, 1974; 2da. ed. Buenos Aires: Alfa Argentina, 1975; 3ra. ed. México: Nueva Imagen/Alfa Argentina, 1977; México: Nueva Imagen/Alfa Argentina, 1978; 5a. ed. [No autorizada]. Bogotá; 6a. ed. México: Nueva Imagen/Alfa Argentina, 1979; 7a. ed. México: Nueva Imagen/Alfa Argentina, 1979.

La casa y el ladrillo. Ira. ed. México, D.F.: Siglo XXI, enero 1977; 2da. ed. México, D.F.: Siglo XXI, junio 1977; 3ra. ed. México, D.F.: Siglo XXI, marzo 1978; 4a. ed. México, D.F.: Siglo XXI, noviembre 1978; 5a. ed. México, D.F.: Siglo XXI.

Cotidianas. 1ra. ed. México, D.F.: Siglo XXI, marzo 1979; 2da. ed. México, D.F.: Siglo XXI, junio 1979; 3a. ed. México, D.F.: Siglo XXI, 1980.

"Rodolfo convirtió la realidad". Casa de las Américas (La Habana), No. 121, julio-agosto 1980, p. 49.

"Semántica". Caliban (Amherst, Massachusetts), Vol. 2, No. 2, 1980, p. 88. 


\section{B. PROSA}

1. Novelas

Quién de nosotros. 1 ra. ed. Montevideo: Número, 1953; 2da. ed. Montevideo: Alfa, 1962; 3ra. ed. Montevideo: Alfa, 1967; 4a. ed. Montevideo: Alfa, 1969; 5a. ed. Madrid: Círculos de Lectores, 1975; 6a. ed. Buenos Aires: Alfa Argentina, 1974; 7a. ed. Buenos Aires: Alfa Argentina, 1974; 8a. ed. México, D.F.: Nueva Imagen/Alfa Argentina, 1977; 9a. ed. México, D.F.: Nueva Imagen/Alfa Argentina, 1978; 10a. ed. México, D.F.: Nueva Imagen/Alfa Argentina, febrero 1979; 11a. ed. México, D.F.: Nueva Imagen, agosto 1979. [Premio Cámara del Libro 1963].

La tregua. 1ra. ed. Montevideo: Alfa, 1960; 2a. ed. Montevideo: Alfa, 1963; 3ra. ed. Montevideo: Alfa, 1966; 4a. ed. Montevideo: Alfa, 1967;5a. ed. Montevideo: Alfa, 1969; 6a. ed. México, D.F.: Diógenes, 1969; 7a. ed. Montevideo: Alfa, 1970; 8a. ed. Santiago de Chile: Universitaria, 1970; 9a. ed. Montevideo: Alfa, 1970; 10a. ed. Montevideo: Alfa, 1971; 11a. ed. Buenos Aires: Alfa Argentina, 1972; 12a. ed. Barcelona: Planeta, 1973; 13a. ed. Santiago de Chile: Universitaria, 1973; 14a. ed. Buenos Aires: Alfa Argentina, 1974; 15a. ed. Buenos Aires: Alfa Argentina, 1974; $16 \mathrm{a}$. ed. Buenos Aires: Alfa Argentina, 1974; 17a. ed. Buenos Aires: Alfa Argentina, 1974; 18a. ed. Buenos Aires: Alfa Argentina, 1974; 19a. ed. Buenos Aires: Alfa Argentina, 1974; 20a. ed. Buenos Aires: Alfa Argentina, 1975; 21a. ed. México, D.F.: Diógenes, 1976; 22a. ed. Santiago de Chile: Universitaria, 1977; 23a. ed. Madrid: Cátedra, 1978; 24a. ed. México, D.F.: Nueva Imagen, 1979; 25a. ed. México, D.F.: Nueva Imagen, 1979; 26a. ed. La Habana: Arte y Literatura, 1979; 27a. ed. [50,000 ejemplares]. México, D.F.: 1980. [Premio Municipal de Literatura 1960]

Gracias por el fuego. 1 1ra. ed. Montevideo: Alfa, mayo 1975; 2da. ed. Montevideo: Alfa, septiembre 1965; 3ra. ed. Montevideo: Alfa, 1966; 4a. ed. Montevideo: Alfa, 1968; 5a. ed. Montevideo: Alfa, 1969; 6a. ed. México, D.F.: Era, 1969; 7a. ed. La Habana: Casa de las Américas, 1969; 8a. ed. Montevideo: Alfa, 1971; 9a. ed. Montevideo: Alfa, 1972; 10a. ed. México, D.F.: Era, 1973;11a. ed. Barcelona: Laia, 1974; 12a. ed. Buenos Aires: Alfa Argentina, 
septiembre 1974; 13a. ed. Buenos Aires: Alfa Argentina, octubre 1974; 14a. ed. Buenos Aires: Alfa Argentina, 1975; 15a. ed. México, D.F.: Era, 1975; 16a. ed. México, D.F.: Era, 1976; 17 a. ed. Buenos Aires: Alfa Argentina, 1976; 18a. ed. México, D.F.: Era, 1978; 19a. ed. México, D.F.: Era, 1979; 20a. ed. México, D.F.: Era, 1979; 21a. ed. México, D.F.: Era, 1980. [Finalista Premio Biblioteca Breve 1963, Ed. Seix Barral, Barcelona]

El cumpleaños de Juan Angel. 1ra. ed. [Novela en verso]. México, D.F.:

Siglo XXI, 1971; 2da. ed. Montevideo: Biblioteca de Marcha, 1971; 3ra. ed. Montevideo: Biblioteca de Marcha, 1971; 4a. ed. Montevideo: Biblioteca de Marcha, 1971; 5a. ed. México, D.F.: Siglo XXI, 1972; 6a. ed. México, D.F.: Siglo XXI, abril 1973; 7 a. ed. México, D.F.: Siglo XXI, octubre 1973; 8a. ed. México, D.F.: Siglo XXI, 1974; 9a. ed. Buenos Aires: Siglo XXI, Argentina, 1974; 10a. ed. Buenos Aires: Siglo XXI, Argentina 1975; 1la. ed. México, D.F.: Siglo XXI, 1975; 12a. ed. La Habana: Casa de las Américas, 1976; 13a. ed. México, D.F.: Siglo XXI, 1976; 14a. ed. México, D.F.: Siglo XXI, 1977; 15a. ed. México, D.F.: Siglo XXI, 1978; 16a. ed. México, D.F.: Siglo XXI, 1978; 17a. ed. México, D.F.: Siglo XXI, 1979; 18a. ed. México, D.F.: Siglo XXI, 1980.

\section{Cuentos}

"Esta mañana". 1ra. ed. Montevideo: Imprenta Prometeo, 1949; 2da. ed. [Aumentada, con título Esta mañana y otros cuentos]. Montevideo: Arca, 1967; 3ra. ed. Montevideo: Arca, 1968; 4a. ed. Montevideo: Arca, 1972; 5a. ed. Buenos Aires: Arca/Calicanto, 1976; 6a. ed. Buenos Aires: Arca/Calicanto, 1976. [Premio Ministerio de Instrucción Pública 1950]

El último viaje y otros cuentos. Montevideo: Número, 1950. [La mayoría de los cuentos que integran este volumen fueron incluidos posteriormente en Esta mañana y otros cuentos y en Montevideanos ]

"Familia Iriarte". En: Latcham, Ricardo. Antologia del cuento hispanoamericano. Santiago de Chile: Zig Zag, 1958, pp. 440-445.

"Familia Iriarte". En: Alegría, Fernando. Novelistas contemporáneos hispanoamericanos. Boston: D.C. Heath, 1964, pp. 184-196. 
"Familia Iriarte". En: Castro Arenas, Mario. El cuento en Hispanoamérica. Lima: Librería Studium, 1974, pp. 291-296.

"Fábulas sin moraleja". Marcha (Montevideo), 16 enero 1959, p. 24. [14 micro-cuentos]

Montevideanos. 1ra. ed. Montevideo: Alfa, 1959; 2a. ed. [Aumentada] Montevideo: Alfa, 1962; 3ra. ed. Montevideo: Alfa, 1964; 4a. ed. Montevideo: Alfa, 1967; 5a. ed. La Habana: Casa de las Américas, 1968; 6a. ed. Montevideo: Centro Editor de América Latina, 1968; 7a. ed. Montevideo: Alfa, 1969; 8a. ed. Montevideo: Alfa, 1971; Buenos Aires: Alfa Argentina, 1975; 10a. ed. Buenos Aires: Alfa Argentina, 1975; 11a. ed. México, D.F.: Nueva Imagen/Alfa Argentina, 1978; 12a. ed. México, D.F.: Nueva Imagen/Alfa Argentina, 1979. [Premio Municipal de Literatura 1959]

"Sábado de Gloria". Marcha (Montevideo), 22 mayo 1960, pp. 20, 21.

"Sábado de Gloria". En: Visca, Arturo Sergio. Los del cuarenta y cinco. Antología del cuento uruguayo. Vol. 5. Montevideo: Banda Oriental, 1968, pp. 81-87.

"Retrato de Elisa". En: Visca, Arturo Sergio. Antologia del cuento uruguayo contemporáneo. Montevideo: Universidad de la República, 1962, pp. 434-441.

"Retrato de Elisa". En: Constenla, Julia. Crónicas de América. Buenos Aires: Jorge Alvarez, 1965, pp. 113-124.

“Tan amigos". En: Visca, Arturo Sergio. Antología del cuento uruguayo contemporáneo. Montevideo: Universidad de la República, 1962, pp. 429-433.

"Tan amigos". En: Lugones, Piri. Los diez mandamientos. [Antología]. Buenos Aires: Jorge Alvarez, 1966, pp. 127-134.

"Tan amigos". En: Rodríguez Alcalá, Hugo y Rodríguez Alcalá, Sally. Cuentos nuevos del sur. Englewood Cliffs: Prentice Hall, 1967.

"Los pocillos". En: Visca, Arturo Sergio. Antologia del cuento uruguayo contemporáneo. Montevideo: Universidad de la República, 1962, pp. 442-448.

"Los pocillos". Alma Mater (La Habana), No. 129, 15 abril 1972, p. 12.

"Corazonada". En: Alegría, Fernando. Novelistas contemporáneos hispanoamericanos. Boston: D.C. Heath, 1964, pp. 192-196. 
"Corazonada". En: Gómez Benoit, Abelardo. Antología contemporánea del cuento hispanoamericano. Lima: Instituto Latino-Americano de Vinculación Cultural, 1964, pp. 233-237.

"El presupuesto". En: Franco, Jean. Short Stories in Spanish. [Edición bilingüe]. Harmondsworth: Penguin, 1966, pp. 27-41.

"El presupuesto". En: Cotelo, Rubén. Narradores uruguayos. Caracas: Editorial Monte Avila, 1969, pp. 203-211.

"El presupuesto". En: Visca, Arturo Sergio. Alborada: cuentos de hoy. Montevideo: Cisplatina, s.f.

"Esa boca". En: Rodríguez Alcalá, Hugo y Rodríguez Alcalá, Sally. Cuentos nuevos del sur. Englewood Cliffs: Prentice Hall, 1967.

Datos para el viudo. Buenos Aires: Editorial Galerna, 1967. [Obra incluida posteriormente en La muerte y otras sorpresas, México, Siglo XXI, 1968]

"Cinco años de vida". En: Somers, Armonía. La otra mitad del amor. [Antología]. Montevideo: Arca, 1968, pp. 24-34.

"Ganas de embromar". En: Piglia, Ricardo. Crónica de Latinoamérica. Buenos Aires: Jorge Alvarez, 1968, pp. 171-178.

"Ganas de embromar." En: Siete cuentos de hoy. [Benedetti et al]. Montevideo: Editorial Sandino, 1973, pp. 7-13.

"Ganas de embromar". En: Lewald, H. Ernest y Yates, Donald. Comp. El espiritu de la juventud. Englewood Cliffs: Prentice Hall, 1981, pp. 45-50. [Con nota bío-bibliográfica]

“Miss Amnesia". En: Llopis, Rogelio. Cuentos Fantásticos. La Habana: Instituto Cubano del Libro, 1968, pp. 111-116.

"Puntero izquierdo". En: Galeano, Eduardo. Comp. Su majestad el fútbol. Montevideo: Arca, 1968.

"Puntero izquierdo". En: Rodríguez, Mario. Castellano: antología y apuntes de teoría literaria. Santiago: Centro de Perfeccionamiento, Experimentación e Investigación Pedagógicas, 1970, pp. 51-54.

"Puntero izquierdo". En: Rodríguez, Mario. Cuentos hispanoamericanos. [Antología]. Santiago de Chile: Editorial Universitaria, 1970, pp. 212-217.

La muerte y otras sopresas. 1ra. ed. México, D.F.: Siglo XXI, 1968; 2 da. ed. México, D.F.: Siglo XXI, 1969; 3ra. ed. México, D.F.: Siglo XXI, 1969; 4a. ed. Montevideo: Alfa, 1969; 5a. ed. Montevideo: 
Alfa, 1971; 6a. ed. México, D.F.: Siglo XXI, 1972; 7a. ed. México, D.F.: Siglo XXI, 1973; 8a. ed. México, D.F.: Siglo XXI, 1974; 9a. ed. México, D.F.: Siglo XXI, 1975; 10a. ed. Buenos Aires: Alfa Argentina, 1975; 11a. ed. Buenos Aires: Alfa Argentina, 1975; 12a. ed. México, D.F.: Siglo XXI, 1975; 13a. ed. México, D.F.: Siglo XXI, 1976; 14a. ed. México, D.F.: Siglo XXI, 1977; 15a. ed. México, D.F.: Siglo XXI, febrero 1978; 16a. ed. México, D.F.: Siglo XXI, agosto 1978; 17a. ed. México, D.F.: Siglo XXI, marzo 1979; 18a. ed. México, D.F.: Siglo XXI, septiembre 1979.

"Los novios". En: Sarlo Sabajanes, B. Cuentos de dos orillas. [En colaboración con Luis Gregorich]. Buenos Aires: Centro Editor de América Latina, 1971, pp. 17-37.

"Niñoquepiensa". En: Alfaro, Hugo R. Comp. Los Humoristas. Montevideo: Biblioteca de Marcha, Colección Antología/2, 1971, pp. 100102.

"Señorita en picada". En: Alfaro, Hugo R. Comp. Los Humoristas. Montevideo: Biblioteca de Marcha, Colección Antología/2, 1971, pp. 209-211.

"Relevo de pruebas". Santiago (Santiago de Chile), No. 2-3, junio 1971, pp. 102-110.

"Relevo de pruebas". En: Torres Fierro, Danubio. Cuentos de la revolución. [Antología]. 1ra. ed. Montevideo: Girón, 1971, pp. 1727; 2da. ed. Montevideo: Girón, 1972, pp. 17-27.

"Se acabó la rabia". Cuba Tabaca (La Habana), Vol. 2, No. 2, abril-junio 1972 , pp. 62-65.

Cuentos completos. [Prólogo de Jorge Ruffinelli]. 1ra. ed. Santiago de Chile: Editorial Universitaria, 1970; 2da. ed. Santiago de Chile: Editorial Universitaria, 1973.

Con y sin nostalgia. México, D.F.: Siglo XXI, 1977; 2da. ed. México, D.F.: Siglo XXI, 1978; 3ra. ed. México, D.F.: Siglo XXI, 1979; 4a. ed. México, D.F.: Siglo XXI, 1980.

Todos los cuentos de Mario Benedetti. [Incluye los libros: Esta mañana, Montevideanos, La muerte y otras sorpresas, Con y sin nostalgia]. La Habana: Casa de las Américas, 1980. 
3. Ensayos

a. Comentarios literarios

Peripecia y novela. [Edición del autor]. Montevideo: Imprenta Prometeo, 1948. [Premio Ministerio de Instrucción Pública 1949]

"William Faulkner, un novelista de la fatalidad". Número (Montevideo), Vol. 2, No. 10-11, septiembre-diciembre, 1950, pp. 563-571.

"Para una revisión de Carlos Reyles". En: Rodríguez Monegal, Emir. La literatura uruguaya del 900. Montevideo: Número, 1950, pp. 187197.

"Para una revisión de Carlos Reyles". En: Paganini, Alberto. La crítica del 45. [Antología]. Biblioteca uruguaya fundamental: 35. Montevideo: Centro Editor de América Latina, 1968, pp. 7-17.

Marcel Proust y otros ensayos. Montevideo: Número, 1951. [Premio Ministerio de Instrucción Pública 1951]

"Cambio de sueños: arraigo y evasión en la actual literatura uruguaya". Revista de la Universidad de México (México, D.F.), Vol. 16, No. 7 marzo 1962, pp. 10-17.

Literatura uruguaya siglo XX. 1ra. ed. Montevideo: Alfa, 1963; 2da. ed. [Aumentada]. Montevideo: Alfa, 1969. [Premio Municipal de Literatura 1963]

"Carlos Fuentes: una dramática conciencia americana". Tiempos modernos (Buenos Aires), Vol. 1, No. 1, 1964, pp. 9-10, 12.

"Literatura uruguaya siglo XX". En: Latcham, Ricardo. Antología. Crónica de varia lección. Santiago de Chile: Zig-Zag, 1965, pp. 165-169.

Genio y figura de José Enrique Rodó. Buenos Aires: Eudeba, 1966.

Letras del continente meztizo. 1ra. ed. Montevideo: Arca, 1967; 2da. ed. [Aumentada]. Montevideo: Arca, 1969; 3ra. ed. [Aumentada]. Montevideo: Arca, 1974.

"Poesía desde el cráter". Marcha (Montevideo), Vol. 29, No. 1328, 12 diciembre 1967, pp. 30-31.

"Sobre la función social del escritor". [Benedetti et al]. Revista de la Casa de las Américas (La Habana), No. 43, 1967, pp. 102- 113.

"Vallejo y Neruda: dos modos de influir". Revista de la Casa de las Américas (La Habana), No. 43, 1967, p. 91. 
"La vigilia dentro del sueño". En: Letras del continente mestizo. Montevideo: Arca, 1967, pp. 191-201.

"La vigilia dentro del sueño". En: Nueve asedios a García Márquez. Santiago de Chile: Editorial Universitaria, 1971, pp. 7-21.

“La vigilia dentro del sueño”. En: Simón Martínez, Pedro. Sobre García Márquez, 1ra. ed. uruguaya. [Aumentada]. Montevideo: Biblioteca de Marcha, 1971, pp. 99-105.

"Sobre las relaciones entre el hombre de acción y el intelectual". Islas, (Santa Clara), Vol. 10, No. 3, julio-septiembre 1968, pp. 30-45.

Sobre artes y oficios: ensayo. Montevideo: Alfa, 1968.

"El boom entre libertades, I". Marcha (Montevideo), Vol. 30. No. 1434, 24 enero 1969 , pp. 30-31.

"El boom entre libertades, II". Marcha (Montevideo), Vol. 30, No. 1435, 31 enero 1969 , p. 31.

“Conversación con Roque Dalton, I". Marcha (Montevideo), Vol. 30, No. 1438, 28 febrero 1969 , pp. 30-31.

"Conversación con Roque Dalton, II". Marcha (Montevideo), Vol. 30, No. 1439, 7 marzo 1969 , p. 30.

"Los temas del novelista hispanoamericano". En: Loveluck, Juan. La novela hispanoamericana. Santiago de Chile: Editorial Universitaria, 1969, pp. 127-136.

“Del testimonio a la metáfora". Casa de las Américas (La Habana), Vol. 11, No. 64, enero-febrero, 1971, pp. 177-179.

"Sobre métodos y abismos". Marcha (Montevideo), Vol. 32, No. 1542, 7 mayo 1971, p. 11.

"Las prioridades del escritor". Casa de las Américas (La Habana), Vol. 12, No. 68, septiembre-octubre 1971, pp. 70-79.

"La actual literatura de Uruguay". En: Panorama de la actual literatura latinoamericana. Caracas: Fundamentos, 1971, pp. 157-186.

Crítica cómplice. La Habana: Instituto Cubano del Libro, 1971.

"Juan Carlos Onetti y la aventura del hombre". En: Flores, Angel y Silva Cáceres, Raúl, Comp. La novela hispanoamericana actual. Compilación de ensayos críticos. Nueva York: Las Américas, 1971, pp. 72-90.

Rodó: parábolas y textos escogidos. Montevideo: Fundación Editorial Unión del Magisterio, 1971. 
"Situación actual de la cultura cubana". En: Riera, Iguasi. Literatura y arte nuevo en Cuba. Barcelona: Editorial Estela, 1971, pp. 7-32.

"Situación del intelectual en la América Latina". [Ensayo]. En: Riera, Iguasi. Literatura y el arte nuevo en Cuba. Barcelona: Editorial Estela, 1971, pp. 145-152.

Los poetas comunicantes. [Reportaje]. Montevideo: Biblioteca de Marcha, 1972.

"La aventura del hombre". En: Ruffinelli, Jorge. Comp. Mario Benedetti: variaciones críticas. Montevideo: Libros del Astillero, 1973, pp. 21-47.

El escritor latinoamericano y la revolución posible. 1ra. ed. Buenos Aires: Alfa Argentina, 1974; 2da. ed. Caracas: Latinoamericana de Ediciones, 1977; 3ra. ed. México: Nueva Imagen/Alfa Argentina, 1977; 4a. ed. México: Nueva Imagen/Alfa Argentina, 1978; 5a. ed. México: Nueva Imagen/Alfa Argentina, 1979; 6a. ed. México, D.F.: Nueva Imagen, 1980.

El recurso del supremo patriarca. 1ra. ed. Buenos Aires: Alfa Argentina, 1974; 2a. ed. México, D.F.: Nueva Imagen, 1977; 3a. ed. México, D.F.: Nueva Imagen, 1978; 4a. ed. México, D.F.: Nueva Imagen, 1979.

"Paco Urondo: Constructor de optimismos". Casa de las Américas (La Habana), Vol. 101, 1977, pp. 17-24.

"El escritor y la crítica en el contexto del subdesarrollo". Arte, Sociedad, Ideología (México, D.F.), No. 3, 1977, pp. 4-21.

"El escritor y la crítica en el contexto de subdesarrollo". Casa de las Américas (La Habana), Vol. 107, 1978, pp. 3-21.

"La cultura del hombre de acción y la creación intelectual". Revista Casa de las Américas (La Habana), No. 107, 1978, pp. 3-21.

"La hazaña de un provinciano". [Ensayo sobre José Soler Puig]. Revista de Crítica Latinoamericana (Lima), Vol. 4, No. 7-8, 1978, pp. 199204.

“Temas y problemas". En: Fernández Moreno, César. América Latina en su literatura. México, D.F.: Siglo XXI, 1979, pp. 354-367.

"Una indagación dramática en la psicología de un torturador". [Comentario sobre Pedro y el capitán ]. El País Libros, suplemento dominical de El País (Madrid), 13 abril 1980, pp. 1, 7. 
b. Comentarios socio-políticos

El país de la cola de paja. 1ra. ed. Montevideo: Asir, 1960; 2a. ed. Montevideo: Ediciones Ciencias, 1961; 3ra. ed. Montevideo: Ciudad Vieja, 1961; 4a. ed. [Ampliada]. Montevideo: Ciudad Vieja, 1961; 5a. ed. Montevideo: Arca, 1966; 6a. ed. Montevideo: Arca, 1967; 7a. ed. Montevideo: Arca, 1968; 8a. ed. [Incluye "Otros temas nacionales"]. Montevideo: Arca, 1970; 9a. ed. Montevideo: Arca, 1973.

"Canjeables e inadaptados". En: Real de Azúa, Carlos. Antología del ensayo uruguayo contemporáneo: Vol. II. Montevideo: Universidad de la República, 1964, pp. 521-524.

"Más o menos nativistas". En: Real de Azúa Carlos. Antología del ensayo uruguayo contemporáneo: Vol. II. Montevideo: Universidad de la República, 1964, pp. 519-521.

"El subsuelo de la calma". En: Real de Azúa, Carlos. Antología del ensayo uruguayo contemporáneo: Vol. II. Montevideo: Universidad de la República, 1964, pp. 518-519.

"Sobre países y personajes". Marcha (Montevideo), Vol. 30, No. 1469, 7 noviembre 1969 , p. 31.

"El terrorismo de la verdad". Marcha (Montevideo), Vol. 31, No. 1470, 14 noviembre 1969, p. 6.

"Pacheco Areco, un hombre providencial". Marcha (Montevideo), Vol. 31, No. 1472,28 noviembre 1969 , p. 8.

"Africa 69: su fuerza y su vulnerabilidad". Casa de las Américas (La Habana), Vol. 10, No. 58, enero-febrero 1970, pp. 39-47.

"Uruguay en un instante decisivo". Pensamiento crítico (La Habana), No. 37, febrero 1970, pp. 221-225.

"Un nuevo rostro para el Uruguay". Bohemia (La Habana), Vol. 62, No. 18 , mayo 1970 , pp. 40-43.

"De cómo la revolución cubana fue hecha tan decisiva". Casa de las Américas (La Habana), Vol. 9, No. 61, julio-agosto 1970.

"Ernesto Cardenal: evangelio y revolución". Casa de las Américas (La Habana), Vol. 10, No. 63, noviembre-diciembre 1970, pp. 174-183.

"Pacheco Areco, un hombre providencial". Revolución y cultura (La Habana), Vol. 5, No. 21, diciembre 1970, pp. 60-62. 
“Analepsia de mi sueldo". En: Alfaro, Hugo R. Comp. Los Humoristas. Montevideo: Biblioteca de Marcha, Colección Antología/2, 1971, pp. 171-173.

"El hinchismo nacional". En: Alfaro, Hugo R. Comp. Los Humoristas Montevideo: Biblioteca de Marcha, Colección Antología/2, 1971, pp. 36-38.

"Europa y esta aldea". En: Alfaro, Hugo R. Comp. Los Humoristas. Montevideo: Biblioteca de Marcha, Colección Antología/2, 1971, pp. 117-119.

"Introducción a la infancia". En: Alfaro, Hugo R. Comp. Los Humoristas. Montevideo: Biblioteca de Marcha, Colección Antología/2, 1971, pp. $140-142$.

"Parca registrada". En: Alfaro, Hugo R. Comp. Los Humoristas. Montevideo: Biblioteca de Marcha, Colección Antología/2, 1971, pp. 187-190.

"Rango del guarango". En: Alfaro, Hugo R. Comp. Los Humoristas. Montevideo: Biblioteca de Marcha, Colección Antología/2, 1971, pp. 18-21.

“'Sálvense quien pueda!” En: Alfaro, Hugo R. Comp. Los Humoristas. Montevideo: Biblioteca de Marcha, Colección Artología/2, 1971, pp. 79-81.

"Una encuesta popular". En: Alfaro, Hugo R. Comp. Los Humoristas. Montevideo: Biblioteca de Marcha, Colección Antología/2 1971, pp. 58-60.

"Verdades de mostrador". En: Alfaro, Hugo R. Comp. Los Humoristas. Montevideo: Biblioteca de Marcha, Colección Antología/2, 1971, pp. 159-161.

"Fe de erratas para el presidente". Marcha (Montevideo), Vol. 32, No. 1527, 8 enero 1971, p. 9.

"Se equivocó, señor". Marcha (Montevideo), Vol. 32, No. 1543, 14 mayo 1971, p. 6.

"Ni sordos, ni mudos, ni ciegos". Marcha (Montevideo), Vol. 32, No. 1545, 18 mayo 1971 , p. 10.

"El triste partido de la desesperación". Marcha (Montevideo), Vol. 33, No. 1553, 23 julio 1971, p. 7.

"También el Presidente dice verdades". Marcha (Montevideo), Vol. 33, No. 1555,6 agosto 1971, p. 31. 
"Los delirios del monarca, o un amor no correspondido". Marcha (Montevideo), Vol. 33, No. 1561, 17 septiembre 1971, p. 6.

"Uruguay, en las puertas del cambio". Nuevo Hombre (Buenos Aires), Vol. 1, No. 7, septiembre 1971, p. 12.

"Una barbarie inútil y costosa". Marcha (Montevideo), Vol. 33, No. 1564, 8 octubre 1971, p. 6.

"La infamia y los asesores". Marcha (Montevideo), Vol. 33, No. 1576, 30 diciembre 1971, p. 6.

"Bartolomé Hidalgo y la buena tentación". En: Cielitos y diálogos patrióticos: con textos de Mario Benedetti y Angel Rama sobre Bartolomé Hidalgo. Montevideo: Biblioteca de Marcha, 1971, pp. 7-10.

"Posdata 1963". En: Mayans, Ernesto. Tupamaros. Cuernavaca: Centro Intercultural de Documentación, 1971, pp. 73-93.

“Raúl Sendic: símbolo de una transformación”. En: Costa, Omar. Comp. Los tupamaros. México, D.F.: Ediciones Era, 1971, pp. 78-83.

“Adiós y malos sueños". Marcha (Montevideo), Vol. 33, No. 1583, 3 marzo 1972, p. 7.

"La cultura pasa a la clandestinidad". Cine Cubano (La Habana), 76-77, marzo-abril 1972, pp. 133-136.

“Canto libre en vida libre". Cine Cubano (La Habana), 76-77, abril-mayo 1972, pp. 146-152.

“¿Por qué es otro país?” Marcha (Montevideo), Vol. 32, No. 1539, 7 abril 1972, p. 6.

"Que pague la oligarquía". Marcha (Montevideo), Vol. 33, No. 1587, 7 abril 1972, p. 6.

“Otras formas de la violencia”. Marcha (Montevideo), Vol. 33, No. 1589, 21 abril 1972, p. 6.

Crónicas del 71. Montevideo: Arca, 1972.

"Emigración que acusa”. En: "Uruguay y ¿Ahora Qué? [Número especial]. Cuadernos de Crisis (Buenos Aires), No. 4, 1973?, pp.105-106.

Terremoto y después. Montevideo: Arca, 1973.

"Notas sobre algunas formas subsidiarias de la penetración cultural". Universidad de La Habana (La Habana), No. 206, abril-diciembre, 1977, pp. 21-41. 
"La cultura del hombre de acción y la creación intelectual". Texto Crítico (Vera Cruz), No. 14, 1979, pp. 44-57.

"Política y cultura en Uruguay 1976". Santiago (Santiago de Chile), No. 31, 1978, pp. 9-36.

Algunas formas subsidiarias de la penetración cultural. [Ensayo]. México, D.F.: Ed. Tierra Adentro, enero 1979.

\section{TEATRO}

Ustedes, por ejemplo. Montevideo: Número, 1953.

El reportaje. Montevideo: Marcha, 1958. [Premio Ministerio de Instrucción Pública 1958].

Ida y vuelta. Buenos Aires: Talía, 1963. [Obra premiada en las Primeras Jornadas de Teatro Nacional y en el Concurso de Obras Teatrales de El Galpón]

"Ida y vuelta". En: Solórzano, Carlos. El teatro hispanoamericano contemporáneo. Vol. 1, México, D.F.: Fondo de Cultura Económica, 1964, pp. 64-123.

Dos comedias. [Incluye "El reportaje" e "Ida y vuelta"]. Montevideo: Alfa, 1968.

Pedro y el capitán. México, D.F.: Nueva Imagen, 1979. [Obra estrenada por el elenco de El Galpón, México, marzo 1979]

\section{ANTOLOGIAS Y PROLOGOS}

Onetti, Juan Carlos. Un sueño realizado y otros cuentos. [Prólogo]. Montevideo: Número, 1951.

Narradores rumanos. Montevideo: Alfa, 1965.

Rubén Dario: Poesias. La Habana: Casa de las Américas, 1967.

Galeano, Eduardo. Los fantasmas del día del león y otros cuentos. [Prólogo]. Montevideo: Arca, 1967.

García Márquez, Gabriel. Cien años de soledad. [Prólogo]. Colección Latinoamericana Hoy. La Habana: Casa de las Américas, 1968.

Onetti, Juan Carlos. El astillero. [Prólogo]. La Habana: Casa de las Américas, 1968. 
Naturaleza Viva/Unstill Life: an Introduction to the Spanish Poetry of Latin America. [Texto bilingüe, traducido por Darwin J. Flakoll y Claribel Alegría]. Nueva York: Harcourt, Brace and World, 1969.

Poesias de amor hispanoamericanas. 1ra. ed. La Habana: Instituto Cubano del Libro, 1969; 2a. ed. Montevideo: Arca, 1969; 3ra. ed. Montevideo: Arca, 1972. [Las dos ediciones de Arca llevan el título: Poemas de amor hispanoamericanos ].

Quince relatos de la América Latina. [En colaboración con Antonio Benítez Rojo]. La Habana: Casa de las Américas, 1970.

Poesía rebelde uruguaya 1967-71. [En colaboración con Jorge Ruffinelli. Incluye cuatro poemas de M.B.] Montevideo: Biblioteca de Marcha, 1971, pp. 26-31.

Un siglo del relato latinoamericano. [En colaboración con Antonio Benítez Rojo]. La Habana: Casa de las Américas, 1976.

Poesía trunca. 1ra. ed. La Habana: Casa de las Américas, 1977; 2a. ed. Madrid: Visor, 1980.

Jóvenes de esta América. [Poesía]. La Habana: Casa de las Américas, 1978.

Poesia. [Incluye "Conversación con Mario Benedetti", de Roberto Fernández Retamar]. La Habana: Editorial Arte y Literatura, 1980.

\section{E. MISCELANEA}

Mejor es meneallo. [Crónicas humorísticas]. 1ra. ed. Montevideo: Alfa, 1961; 2da. ed. Montevideo: Aquí Poesía, 1965; reedición [Selección de ambas ediciones]. Montevideo: Arca, 1967.

Cuaderno cubano. 1ra. ed. Montevideo: Arca, 1969; 2da. ed. [Aumentada]. Montevideo: Arca, 1971; 3ra. ed. Montevideo: Arca, 1972; 4a. ed. Buenos Aires: Schapire, 1974.

Letras de emergencia. 1ra. ed. Buenos Aires: Alfa Argentina, 1973; 2da. ed. Buenos Aires: Alfa Argentina, 1974; 3ra. ed. México: Nueva Imagen/Alfa Argentina, 1977; 4a. ed. México: Nueva Imagen/Alfa Argentina, 1978; 5a. ed. México: Nueva Imagen/Alfa Argentina, 1979; 6a. ed. México, D.F.: Nueva Imagen, 1980.

Daniel Viglietti. 1ra. ed. Colección los Juglares: 13. Madrid: Ediciones Júcar, 1974; 2da. ed. Buenos Aires: Ediciones La Línea, 1974. 
Hasta aqui. Buenos Aires: Ediciones La Línea y Vaccaro, 1974.

"Alejo Carpentier: un anuncio de la vida". Casa de las Américas (La Habana), No. 122, septiembre-octubre 1980, pp. 96-98. [Palabras pronunciadas en homenaje póstumo].

Mario Benedetti, poemas y cuentos. [Disco con nota biográfica; M.B. lee algunos de sus poemas y cuentos]. La Habana: Casa de las Américas, s.f.

\section{F. TRADUCCIONES DE OBRAS DE MARIO BENEDETTI}

"Birthday in Manhattan". Trads. Margaret Randall y Sergio Mondragón. En: The Plumed Horn/El corno emplumado. [Edición bilingüe]. (México, D.F.), No. 3, julio 1962, pp. 112-119. [Poema "Cumpleaños en Manhattan"]

"Gloria's Saturday." Trads. Darwin J. Flakoll y Claribel Alegría. En: New Voices of Hispanic America. Boston: Beacon Press, 1962, pp. 121127. ["Sábado de Gloria"]

"Il resto é selva." Trad. Enrico Cicogna. En: Le piú belle novelle di tutti $i$ paesi. Milán: Martello, 1963. ["El resto es selva"]

“Der Rest ist Wildnis." Trad. E.A. Nicklas. En: Moderne Lateinamerikanische Prosa. Eds. Andreas Klotsch y Gisela Leber. Berlín: Verlag Volk und Welt, 1971. ["El resto es selva"]

"Familia Iriarte". Trad. D. Hardan Halpern. En: Cuentos latinoamericanos modernos. Tel Aviv: Am Hassefer Ltd., 1964.

"The Iriartes." Trad. Jean Franco. En: Latin American Writing Today. Ed. J.M. Cohen. Harmondsworth: Penguin, 1967 ["Familia Iriarte"]

"The Iriartes." Trad. Lynn Tricario y Suzanne Jill Levine. En: Fiction (Nueva York), Vol. 5, No. 1, 1976. ["Familia Iriarte"]

"Trist pentru întaîa oara." Trad. Nina Cassian. En: Gazeta Literara (Bucarest), 1964. [Poema "Barco viejo"]

"The Budget." Trad. Gerald Brown. En: Short Stories in Spanish/Cuentos hispánicos. [Edición bilingüe]. Ed. Jean Franco. Harmondsworth: Penguin Books, 1966, pp. 27-41. ["El presupuesto"]

“Der Haushaltsplan." Trad. José A. Friedl Zapata. En: Das Haus in der Calle del Socorro/Uruguay in Erzählungen der Besten zeitgnossichen Autoren. Ed. José A. Friedl Zapata. Tübingen y Basel: Horst Erdman Verlag, 1971. [“El presupuesto"] 
"Neuveritelné, co se to dnes deje." Trad. Lumir Civrny. En: Svetova Literatura (Praga), No. 2, 1966. ["Es increíble lo que está pasando", 12 poemas extraídos de Inventario]

"Avo Ruben." Trad. Gianni Toti. Carte Segrete (Roma), No. 2, abril-junio 1967. [“Abuelo Rubén"]

Chvile Oddechu. Trad. Kamil Uhlir. Praga: Odeon, 1967. [La tregua]

Otsrochkata. Trad. Ventseslav Nikolov. Sofía: Narodna Kultura, 1974. [La tregua]

The Truce. Trad. Benjamin Graham. Nueva York: Harper \& Row, 1969. [La tregua]

"Havaneira." Trad. Octavio Mora. En: Revista Civilização Brasileira (Rio de Janeiro), No. 14, Año III, julio 1967. [Poema "Habanera"]

"Kofeinye chashki." Trad. Iura Itannikiev. Nedelia, suplemento dominical de Izvestiia (Moscú), 1968. ["Los pocillos"]

"Such Friends." Trad. Earl Jones. En: Selected Latin American Literature for Youth. Ed. Earl Jones. College Station: Texas A and M University Press, 1968. [“Tan amigos"]

“Der Engel." Trads. Stefan Baciu y Kurt Marti. En: Der Du bist im Exil. Wuppertal-Barmen: Hammer, 1969. [Poema "El ángel"]

"Ein Lateinamerikanisches Vaterunser." Trads. Stefan Baciu y Kurt Marti. En: Der Du bist im Exil. Wuppertal-Barmen: Hammer, 1969. [Poema "Un padrenuestro latinoamericano"]

“Jetzt lohnt es sich". Trads. Stefan Baciu y Kurt Marti. En: Der Du bist im Exil. Wuppertal-Barmen: Peter Hammer Verlag, 1969. [Poema "Ahora vale la pena"]

Spasibo za Ogonëk. Trad. T. Vokhina. En: Inostrannaia literatura (Moscú), Nos. 8 y 9, 1969. [Gracias por el fuego]

Grazie per il fuoco. Trads. Gianni Guadalupe y Marcello Ravoni. Milán: II Saggiatore, 1972. [Gracias por el fuego]

Dziekuje za Ogien. Trad. Monika Garpiel. Cracovia: Wydawntictwo Literackie, 1974. [Gracias por el fuego]

Köszönöm A Tüzet, Uram. Budapest: Europa Konivkiado, 1975. [Gracias por el fuego]

Diky za ohen. Trad. Eduard Hodousek. Praga: Odeon, 1976. [Gracias por el fuego] 
Blagodaria za ognia. Trad. Emilia Yulzari. Bulgaria: Provid, 1978. [Gracias por el fuego]

"Dattilografo." Trads. Marcelo Ravoni y Antonio Porta. En: Poeti ispanoamericani contemporanei. Milán: Feltrinelli, 1970. [Poema "Dactilógrafo"]

"Stusha Na Mashinke." Trad. Perebor B. Slushkii. En: Poeziia Latinskoi Ameriki. Moscú: Biblioteca vsemirnoi literatury, 1975. ["Dactilógrafo"]

"Fatti Miei." Trads. Marcelo Ravoni y Antonio Porta. En: Poeti ispanoamericani contemporanei. Milán: Feltrinelli, 1970. [Poema "Cosas de uno"]

"Nemico." Trads. Marcelo Ravoni y Antonio Porta. En: Poeti ispanoamericani contemporanei. Milán: Feltrinelli, 1970. [Poema "Enemigo"]

"Sa vendicarse." Trads. Marcelo Ravoni y Antonio Porta. En: Poeti ispanoamericani contemporanei. Milán: Feltrinelli, 1970. [Poema "Sabe vengarse"]

“Was für ein Witz." Trad. José A. Friedl Zapata. En: Das Haus in der Calle del Socorro/Uruguay in Erzählungen der besten zeitgnossichen Autoren. Ed. José A. Friedl Zapata. Tübingen Basel: Horst Erdman Verlag, 1971. ["Ganas de embromar"]

Juan Angel's Birthday. [Edición especial, invierno-primavera]. Trad. David Arthur McMurray. Amherst, Mass.: Universidad de Massachusetts, 1974. [El cumpleaños de Juan Angel]

“Angelus". Trad. Perebor B. Slushkii. En: Poeziia Latinskoi Ameriki. Moscú: Biblioteka vsemirnoi literatury, 1975. [Poema "Angelus"]

"Novichok." Trad. Perebor B. Slushkii. En: Poeziia Latinskoi Ameriki. Moscú: Biblioteka vsemirnoi literatury, 1975; ["Balada del empleado nuevo"]

"Ballade von neuen Angestellten." Trads. Carlos Rincón y Gerda Schatternberg-Rincón. En: Cantaré: Songs aus Lateinamerika. Berlín: Verlag Neues Leben, 1978. [Poema "Balada del empleado nuevo"]

Daniel Viglietti: Chansons pour notre Amérique. Trad. Annie Morvan. Paris: Les Editions du Cerf, 1978. [Daniel Viglietti: Canciones para nuestra América ]

Rasskazy. [Antología de cuentos]. Trad. S. Istanskii. Moscú: Progress, 1977. [Cuentos] 
Avec et sans Nostalgie. [Antología de cuentos]. Trad. Annie Moran. París: François Maspero, 1978. [Con y sin nostalgia]

"Mozart Horen." Trad. Horst Rogmann. En: Hammers Jahrbuch Dritte Welt. Ed. Kay-Michael Schreiner. Wuppertal: Peter Hammer Verlag, 1978. ["Escuchar a Mozart"]

"Pequebu." Trads. Carlos Muller, Carolina Dobring y Heinz G. Schmidt. En: Wir haben keine Zeit zu verlieren: Lateinamerikannische Autoren im Exil. Eds. Jacinta Veray y Heinz G. Schmidt. Wuppertal: Peter Hammer, Verlag, 1978. ["Pequebú"]

"Theorie und Praxis." Trads. Carlos Mueller, Carolina Dobring y Heinz G. Schmidt. En: Wir haben keine Zeit zu verlieren: Lateinamerikanische Autoren im Exil. [Antología]. Wuppertal: Peter Hammer Verlag, 1978. [Poema "Teoría y práctica"]

"Zur Situation des Intellectuellen in Lateinamerika." Trad. Horst Rogmann. En: Hammers Jahrbuch dritte Welt. Ed. Kay-Michael Schreiner. Wuppertal: Peter Hammer Verlag, 1978. ["Situación del escritor en América Latina"]

"Omtrent de uittrocht." Traducido al holandés. En: Alerta (Amsterdam), año 5, No. 49-50, enero-febrero 1979, pp. 20-21. ["Sobre el exilio"]

"Uma outra Noção de Patria." Trad. José María Martins Caetano. En: Poesía Uruguaia de Combate. Luanda: Cadernos da União, União dos Escritores Angolanos, 1979. [Poema "Otra noción de patria"]

"Semantics." Trad. David A. McMurray. Caliban (Amherst, Mass.), Vol. 2, No. 2, 1980, p. 89. [Poema "Semántica"]

\section{SOBRE MARIO BENEDETTI}

Achugar, Hugo: "Las sorpresas y otro Benedetti." [Nota bibliográfica sobre La muerte y otras sorpresas ]. Brecha (Montevideo), No. 2, septiembre 1969.

Aguirre González, Adolfo: "A propósito de El pais de la cola de paja. Mirar desde abajo." El Sol (Montevideo), Nos. 9, 16 y 23, diciembre 1960 . 
Aguirre, Mariano. "El escritor uruguayo Mario Benedetti en Madrid: 'Creando arte respondemos a la dictadura'." [Entrevista]. Diario 16 (Madrid), 8 marzo 1980, p. 23.

Aínsa Amigues, Fernando. "Gracias por el fuego (II): La herida de lo cotidiano." [Reseña crítica]. Epoca (Montevideo), 11 agosto 1965, p. 10.

. "Los novelistas del 45 - Mario Benedetti: La herida de lo cotidiano." Capítulo Oriental (Montevideo), No. 33, octubre 1968, pp. 524-525.

. "Un preocupado medio intenta ser parricida." [Reseña crítica sobre Gracias por el fuego]. Epoca (Montevideo), 4 agosto 1965.

Tiempo reconquistado: siete ensayos sobre literatura uruguaya. Montevideo: Ediciones Geminis, 1977. [Incluye un ensayo sobre M.B.]

Albero, Rosel. "Diálogo con Mario, Benedetti." [Entrevista]. Los Andes (Mendoza), 8 marzo 1970, p. 2.

Alegría, Fernando. "Mario Benedetti." En su: Historia de la novela latinoamericana. 3ra. ed. México, D.F.: Ediciones de Andrea, 1966, pp. 235-236.

"Una semblanza." En: Ruffinelli, Jorge. Comp. Mario Benedetti: variaciones críticas. Montevideo: Libros del Astillero, 1973, pp. 171-172.

Altamirano, Carlos. Poesía del siglo XX: España e Hispanoamérica. [Nota bio-bibliográfica]. Buenos Aires: Centro Editor de América Latina, 1971, p. 65.

Alvarez, Federico. "Quién de nosotros." [Nota bibliográfica]. ;Siempre! (México, D.F.), No. 106, 26 febrero 1964.

"Quién de nosotros: un punto de partida." En: Fornet, Ambrosio. Comp. Recopilación de textos sobre Mario Benedetti. La Habana: Casa de las Américas, 1976, pp. 115-126.

Alzueta, Miguel. "Mario Benedetti, entre mil aguas." [Entrevista]. El Viejo Topo (Barcelona), No. 44, mayo 1980, pp. 68-70.

Andrés, Jorge. "Sobre poemas de Mario Benedetti, Nacha Guevara graba un repertorio diferente con notables resultados." [Reseña crítica sobre el disco "Nacha canta Benedetti"]. La Opinión (Buenos Aires), 12 abril 1972. 
Anónimos.

. "El último viaje y otros cuentos." [Reseña]. La Nación (Buenos Aires), 13 abril 1952.

. "Quién de nostros." [Nota bibliográfica]. El Autor Uruguayo (Montevideo), 1954.

. "Quién de nosotros." [Nota bibliográfica]. La Mañana (Montevideo), 1954.

. "Poemas de la oficina." [Reseña]. Acción (Montevideo), 1956.

"El escritor nacional y nuestro medio." [Encuesta]. (El País (Montevideo), 8 diciembre 1957, p. 3.

"Ida y vuelta." [Comentario]. El Diario (Montevideo), 19 julio 1958.

"Un fénix poco frecuente." [Reseña crítica sobre La tregua ]. Suplemento dominical de El Día (Montevideo), 1960.

. "La tregua." [Nota bibliográfica]. El Debate (Montevideo), 16 enero 1961.

."El país de la cola de paja." [Reseña]. Política (Montevideo), febrero-abril 1961, p. 77.

"Mario Benedetti: esa implacable memoria de la izquierda." [Reportaje]. Epoca (Montevideo), 5 enero 1963, p. 6.

. "Mario Benedetti obtuvo un premio internacional." [Sobre Premio Biblioteca Breve 1963, Ed. Seix Barral, en el que Gracias por el fuego fue finalista]. El Diario (Montevideo), enero 1963.

. "Cinco preguntas semanales: contesta Mario Benedetti." Epoca (Montevideo), 14 abril 1963, p. 11.

. "Los oficinistas no tienen salvación." [Reseña crítica sobre $L a$ tregua]. Primera Plana (Buenos Aires), No. 61, 7 enero 1964.

" "La hermosa simplicidad." [Incluye comentario sobre La tregua]. Panorama (Buenos Aires), febrero 1964, pp. 23-24.

. "La aldea se alborota. Benedetti: es cierto, me voy, pero siempre para volver." Epoca (Montevideo), 3 septiembre 1965, p. 9.

"14 veces Benedetti; confesión aniversario." [Reportaje]. Epoca (Montevideo), 1965. 
"Genio y figura de José Enrique Rodó." [Reseña]. La Nación (Buenos Aires), 7 agosto 1966.

. "La tregua." [Nota bibliográfica]. La Nación (Buenos Aires), 14 agosto 1966.

. "La pobre y buena gente." [Reseña crítica de La tregua]. Confirmado (Buenos Aires), 25 agosto 1966, pp. 52-53.

"Contra los puentes levadizos." [Reseña]. Times Literary Supplement (Londres), 7 diciembre 1967, p. 1190.

"Cómo juzga el exigente Times de Londres, la novela hispanoamericana." [Incluye comentarios sobre Montevideanos, La tregua y Gracias por el fuego]. iSiempre! (México, D.F.), 1967. . "Benedetti cuenta la historia." [Reportaje]. Bohemia (La Habana), 14 abril 1967. “Inventario 67." [Reseña]. Idea (Lima), Año XVIII, Nos. 67-68, enero-junio 1967.

. "Mario Benedetti: señor de los tristes." Margen (París), No. 3-4, 1967, pp. 62-65.

. "Ternura por los hombres grises." [Reseña sobre Inventario 67, Datos para el viudo y Quién de nosotros]. Análisis (Buenos Aires), 1 enero 1968.

"Donde disparan con obuses. Análisis crítico de una literatura". [Reseña crítica de Letras del continente mestizo]. Análisis (Buenos Aires), No. 369, 8 abril 1968, pp. 46-47.

. "La hora militante." [Reseña crítica sobre letras del continente mestizo]. Primera Plana (Buenos Aires), No. 282, 21 mayo 1968.

. “Genio y figura de José Enrique Rodó." [Reseña]. Times Literary Supplement (Londres), 20 junio 1968, p. 638.

. "Letras del continente mestizo." [Reseña]. Punto Final (Santiago de Chile), No. 67, noviembre 1968.

. "La vaciedad de la vida." [Reseña crítica sobre La muerte y otras sorpresas]. Primera Plana (Buenos Aires), No. 34, 10 diciembre 1968, pp. 30-31.

. "La muerte y otras sorpresas." [Nota bibliográfica]. La Nación (Buenos Aires), 15 diciembre 1968.

"La muerte y otras sorpresas." [Nota bibliográfica]. Análisis (Buenos Aires), diciembre 1968. 
"La muerte y otras sorpresas." [Nota bibliográfica]. El Heraldo (México, D.F.), 12 enero 1969.

. "La muerte y otras sorpresas." [Reseña]. SP (México, D.F.), Vol. 12, No. 347, 10 febrero 1969, p. 50.

. "Carta abierta a Benedetti." por "uno de esos jóvenes." Marcha (Montevideo), Vol. 30, No. 1437, 14 febrero 1969, p. 3.

"Uruguayan classics." [Incluye comentario a Sobre artes $y$ oficios]. Times Literary Supplement (Londres), 20 marzo 1969, p. 295.

. "Tres preguntas a Mario Benedetti." Extra (Montevideo), 27 mayo 1969 , p. 15.

"Benedetti comprometido." [Reportaje]. Extra (Buenos Aires), No. 49 , agosto 1969 , p. 78 .

"Mario Benedetti: 'Hoy en Uruguay, el que calla no otorga." [Entrevista]. Oriental (Montevideo), 29 agosto 1969, p. 8.

. "Unstill Life/Naturaleza Viva." [Nota bibliográfica]. Kirkus Reviews (USA), 1 octubre 1969.

"Unstill Life/Naturaleza Viva." [Nota bibliográfica]. The Christian Science Monitor (Boston, Mass.), 6 noviembre 1969, p. B10.

"Unstill Life, ed. por Mario Benedetti." [Reseña]. New York Times Book Review (Nueva York), 9 noviembre 1969, p. 7.

"Unstill Life, ed. por Mario Benedetti." [Reseña]. Commonwealth (Londres), No. 91, 21 noviembre 1969, p. 262.

"Cuentos completos." [Reseña]. El Comercio (Lima), 11 octubre 1969.

" "Cuatro siglos de amor." [Reseña de Poemas de amor hispanoamericanos de Mario Benedetti]. El Oriental (Montevideo), 7 noviembre 1969, p. 12.

. "Emoción y testimonio." [Reseña crítica sobre Cuaderno cubano]. El Oriental (Montevideo), 14 noviembre 1969, p. 10.

"La muerte y otras sorpresas." [Reseña]. Imagen (Caracas), No. 61, 15 al 30 noviembre 1969.

"La tregua." [Nota bibliográfica]. Imagen (Caracas), 1 al 15 junio 1970. 
"Drama íntimo." [Nota bibliográfica sobre Gracias por el fuego]. La Prensa (Lima), No. 607, 1 febrero 1970.

."Empathy and alienation." [Incluye comentario sobre La muerte $y$ otras sorpresas]. The Times Literary Supplement (Londres), No. 3577, 18 septiembre 1970, p. 1028.

"6 preguntas a Mario Benedetti." [Reportaje]. Suplemento dominical de El Comercio (Lima), 12 octubre 1970.

"La vida cotidiana." [Nota bibliográfica sobre Cuentos completos]. Análisis (Buenos Aires), No. 506, 24 noviembre - 1 diciembre 1970 , p. 50.

. "Los fuegos de ayer, hogueras de hoy." [Reseña crítica sobre Gracias por el fuego]. Extra (Buenos Aires), julio 1971.

. "Ahora sí, el pueblo sabe cuál es el camino." [Reportaje político]. El Popular (Montevideo), 10 agosto 1971, p. 7.

. "Benedetti: el discurso de 'Seregni es representativo del Frente todo." [Reportaje político]. El Popular (Montevideo), 21 abril 1972.

. "Crónica y moralidades." [Nota bibliográfica sobre Crónicas del 71]. El Popular (Montevideo), 7 julio 1972.

. "Grazie per il fuoco." [Reseña]. Il Mondo (Milán), 7 septiembre 1972. [Gracias por el fuego]

" "Cuaderno cubano." [Reseña]. Vanguardia Dominical (Bucaramanga, Colombia), 10 noviembre 1972.

. "Poeta interroga poetas." [Reseña crítica sobre Los poetas comunicantes]. Ahora (Montevideo), 18 marzo 1973.

Las fuerzas armadas al pueblo oriental. Tomo I. La subversión. [Notas sobre M.B.]. Montevideo: Fuerzas Armadas Uruguayas, 1977, pp. 312, 325, 333.

"Es imposible matar la cultura." América Latina (Moscú), No. 2, 1978, pp. 171-182.

"Mario Benedetti: kultur en politiek." [Entrevista]. Alerta (Amsterdam), No. 57, octubre 1979, pp. 22-23, 36. ["Mario Benedetti: La cultura y la política"]

. "En el Encuentro de Escritores, Benedetti habló del escritor en el exilio." [Comentario sobre intervención en una mesa redonda 
del ciclo El autor y su obra, durante el Encuentro Internacional de Escritores, celebrado en México, mayo 1980]. El Día (México, D.F.), 8 mayo 1980.

"Un escritor en varias direcciones." El País Libros. Suplemento dominical de El Pais (Madrid), 13 abril 1980, p. 6.

Arana Freyre, Elsa. "Deslumbrante Benedetti." [Nota bibliográfica sobre Montevideanos]. La Prensa (Lima), 23 marzo 1964.

Arbeleche, Jorge. "Libertad de uno y de todos." En: Ruffinelli, Jorge. Comp. Mario Benedetti: variaciones críticas. Montevideo: Libros del Astillero, 1973, pp. 176-178.

_. "Mario Benedetti." Eco. (Bogotá), No. 1, 1974, pp. 73-84.

Arias, Salvador. "Benedetti y la buena respiración montevideana." En: Fornet, Ambrosio, Comp. Recopilación de textos sobre Mario Benedetti. La Habana: Casa de las Américas, 1976, pp. 215-221.

Aroca, Santiago. "Entrevista con Mario Bendetti: 'Derrotaremos al partido de la desesperación'." Mundo Obrero (Madrid), 19 marzo 1980, p. 11 .

Baeza, Francisco. "Siempre al pie de la letra." En: Fornet, Ambrosio. Comp. Recopilación de textos sobre Mario Benedetti. La Habana: Casa de las Américas, 1976, pp. 45-58.

Baracchini, Diego. [Nota bibliográfica sobre El cumpleaños de Juan Angel]. Claudia (Buenos Aires), enero 1972.

Bareiro Saguier, Rubén. [Un artículo sobre El cumpleaños de Juan Angel]. Caravelle (Toulouse), No. 17, 1971, pp. 250-253.

. "Autobiografía latinoamericana." En: Ruffinelli, Jorge. Comp. Mario Benedetti: variaciones críticas. Montevideo: Libros del Astillero, 1973, p. 192.

Barrientos, Roberto. [Nota crítica sobre Inventario]. Ensayo Cultural (Buenos Aires), No. 39, 1968.

Barros, Daniel. "Tres poetas de hoy: Teillier, Benedetti y Gelman." En: Castellote, Miguel, Ed. Poesía sudamericana actual. Madrid: s. ed., 1972, pp. 57-58. 
Barros, Salvador. "Historias de amor y de guerrilleros." [Reseña de $E l$ cumpleaños de Juan Angel]. Visión (Nueva York), 14 agosto 1971, p. 60 .

Bazán, Juan F. “Gracias por el fuego.” En su: La novela latinoamericana. Asunción: Diálogo, 1970, pp. 122-127.

. "Montevideanos." En su: La novela latinoamericana. Asunción: Diálogo, 1970, pp. 128-131.

La narrativa latinoamericana. Asunción: Escuela Técnica Salesiana, 1970. [Estudia Gracias por el fuego y Montevideanos].

Beberfall, Freda P. Thematic Continuity and Changing Emphases in the Work of Mario Benedetti. [Thesis]. University of Wisconsin, Madison, 1974.

. "Simbolismo e ideología en El cumpleaños de Juan Angel." [Trad. por Ambrosio Fornet] En: Fornet, Ambrosio. Comp. Recopilación de textos sobre Mario Benedetti. La Habana: Casa de las Américas, 1976, pp. 175-185.

Benvenuto, Sergio. "Prólogo" a Gracias por el fuego. La Habana: Casa de las Américas, Colección Literatura Latinoamericana, 1970.

. "La historia como absurdo y vacio." En: Ruffinelli, Jorge. Comp. Mario Benedetti: variaciones críticas. Montevideo: Libros del Astillero, 1973, p. 183.

Bermúdez, María Elvira. "Dos libros de ERA." [Incluye comentario sobre edición mexicana Gracias por el fuego]. El Nacional (México, D.F.), 5 octubre 1969.

. "El amor en la obra de Benedetti." El Nacional (México, D.F.), No. 167,16 abril 1972.

"El amor en la obra de Mario Benedetti." En: Fornet, Ambrosio. Comp. Recopilación de textos sobre Mario Benedetti. La Habana: Casa de las Américas, 1976, pp. 159-163.

Bernstein de Alberti, Eugenia. Ayer y hoy en las letras uruguayas. [Antología con fines didácticos]. Montevideo: Editorial Medina, s.f., pp. 131-132.

Bertarelli Urdanivia, Eduardo. [Reseña sobre Con y sin nostalgia]. Revista de Crítica Literaria Latinoamericana (Lima), Nos. 7-8, 1978, pp. 212-216. 
Bianqui, Matilde. "Aquí y ahora con Mario Benedetti. 'He inventado verdades que han llegado a ser realidad." Ya Literario, suplemento de $Y a$ (Madrid), 13 marzo 1980, p. 41.

Boldori, Rosa. "El cumpleaños de Juan Ángel: poesía y contrapunto." En: Ruffinelli, Jorge. Comp. Mario Benedetti: variaciones criticas. Montevideo: Libros del Astillero, 1973, pp. 132-146.

Boorman, Joan Rea. "Gracias por el fuego." En su: La estructura del narrador en la novela hispanoamericana contemporánea. Madrid: Hispanova Ediciones, 1976, pp. 79-99.

Bordoli, Domingo Luis. Antología de la poesía uruguaya contemporánea. Montevideo: Universidad de la República, 1960, pp. 90-105.

[Botelho González, Raúl] R.B.G. "Libros nuevos: Quién de Nosotros por Mario Benedetti." [Reseña]. El País (Montevideo), 1954.

Bottone, Mireya. "Gracias por el fuego." [Reseña]. Setecientos monos (Rosario, Argentina), Vol. 3, No. 8, agosto 1966, pp. 21-23.

Bourgonje, Fleur. "Ik heb op Cuba voor uns en altyd antistoffen gekweckt tengen ieder pessimismen." De Groene Amsterdammer (Amsterdam), 8 octubre 1975. ["Creo que en el ejemplo de Cuba tenemos el antídoto contra el pesimismo"]

Bustos Arratia, Myriam. "Benedetti y la poesía." La Nación (San José, Costa Rica), 1 marzo 1979, p. 15A.

"El hombre: ser supremo de la literatura actual." [Nota sobre $E l$ escritor latinoamericano y la revolución posible]. La Nación (San José, Costa Rica), 22 enero 1980, p. 15A.

"América Latina: eslabón que une a sus grandes escritores de hoy." [Nota sobre El escritor latinaomericano y la revolución posible]. La Nación (San José, Costa Rica), 4 abril 1980, p. 15A.

Bustos, Miguel Angel. "El poema que sube la escalera." [Nota bibliográfica de El cumpleaños de Juan Angel]. Panorama (Buenos Aires), 2 noviembre 1971, p. 40.

$\mathrm{C}$

Caballero, Agustín. Antologia del humor 1961-1962. Madrid: Aguilar, 1962. 
Cabrera, Sarandy. "La cola de paja. El último libro de Mario Benedetti." El Popular (Montevideo), 1960.

Campanella, Hortensia. "Mario Benedetti, militante de la vida." [Entrevista]. Triunfo (Madrid), 19 abril 1980, pp. 56-57.

Campos, Julieta. "Inventar la verdad." [Reseña crítica sobre La muerte y otras sorpresas]. 'Siempre! (México, D.F.), 18 diciembre 1968.

"La muerte y otras sorpresas." En su: Oficio de leer. México, D.F.: Fondo de Cultura Económica, 1972, pp. 80-83.

"Humor." En: Ruffinelli, Jorge. Comp. Mario Benedetti: variaciones críticas. Montevideo: Libros del Astillero, 1973, p. 175.

Carrillo, Germán D. "La 'biopsiá como técnica literaria de Mario Benedetti en Gracias por el fuego." Cuadernos Americanos (México, D.F.), No. 177, 1971, pp. 217-233.

Casar, Eduardo. "Sobre Benedetti: evolución de su pensamiento social." Revista de Bellas Artes (México, D.F.), No. 26, marzo- abril 1976, pp. 26-34.

Castiglioni, Juan C. [Reseña sobre Mejor es meneallo, 1ra. serie]. Acción (Montevideo), 16 abril, p. 5.

Castillo, Fausto. “Ahora Uruguay." [Reseña crítica sobre Gracias por el fuego]. El Día (México, D.F.), 18 junio 1969.

Castillos, Alvaro. "Cinco narradores ríoplatenses." Cuadernos hispanoamericanos (Madrid), No. 299, mayo 1975, pp. 479-483.

Castro, Nils. "Benedetti: la moral de los hechos aclara su palabra." Casa de las Américas (La Habana), No. 89, marzo-abril 1975, pp. 78-96.

Casullo, N. "Mercado, 'bestsellers' y política." Nuestros Hijos (Buenos Aires), 1971.

Chao, Ramón. "Mario Benedetti: otro uruguayo, otra literatura, otra crítica y otro hombre." [Entrevista]. Triunfo (Madrid), No. 731, 1977 , pp. 44-45.

Coddou, Marcelo. [Reseña sobre Genio y figura de José Enrique Rodó]. Atenea (Universidad de Concepción, Chile), Vol. 43, No. 162, p. 412.

[Crítica sobre Letras del continente mestizo]. Atenea (Universidad de Concepción, Chile), Vol. 45, No. 166, p. 419. 
"Latcham y Benedetti." En: Ruffinelli, Jorge. Comp. Mario Benedetti: variaciones críticas. Montevideo: Libros del Astillero, 1973, pp. 184-185.

Codina de Giannoni, Iverna. "Un hombre de 45." [Comentario sobre $L a$ tregua]. En su: América en la novela. Buenos Aires: Cruz del Sur, 1964, pp. 175-177.

Collazos, Oscar. "Prólogo" a La tregua. Barcelona: Planeta, 1973.

"Benedetti y las treguas." [Ensayo]. En su: Textos al margen.

Bogotá: Instituto Colombiano de Cultura, 1978, pp. 79-84.

Colominas, Norberto. "El escritor uruguayo Mario Benedetti en Madrid." El País (Madrid), 13 abril 1980, pp. 6-7.

Concha, Edmundo. [Nota bibliográfica sobre Gracias por el fuego]. El Mercurio (Santiago de Chile), 24 abril 1963, p. 3.

. [Nota bibliográfica sobre Montevideanos]. El Mercurio (Santiago de Chile), 3 marzo 1965, p. 5.

"La pobre y buena gente." [Reseña crítica sobre La tregua]. Confirmado (Buenos Aires), 25 agosto 1966, pp. 52-53.

[Notas bibliográficas sobre La tregua]. El Mercurio (Santiago de Chile), 15 octubre 1966, p. 6.

[Notas bibliográficas sobre $E l$ país de la cola de paja]. El Mercurio (Santiago de Chile), 26 abril 1967, p. 3.

"Sólo una tregua." En: Ruffinelli, Jorge. Comp. Mario Benedetti: variaciones críticas. Montevideo: Libros del Astillero, 1973, pp. 179-180.

Constenla, Julia. Crónicas bastante extrañas. [Antología]. Buenos Aires: Ed. Jorge Alvarez, 1965, pp. 67-75.

. Crónicas de América. [Antología]. Buenos Aires: Editorial Jorge Alvarez, 1965, pp. 113-124.

Conteris, Hiber. "El último Benedetti." [Reseña sobre Datos para el viudo y $A$ ras de sueño]. Marcha (Montevideo), Vol. 29, No. 1411, 20 julio 1968, p. 6.

Conti, Haroldo. "La voz del hombre amigo." [Reportaje]. El País Libros, suplemento dominical de El País (Madrid), 13 abril 1980, p. 7. 
Cosentino, Ivan. "Nacha Guevara canta Mario Benedetti." [Nota crítica sobre el disco "Nacha canta Benedetti"]. Clarin (Buenos Aires), 15 junio 1972.

Cotelo, Rubén. "Aquí y ahora." [Nota bibliográfica sobre Montevideanos]. El Pais (Montevideo), 24 enero 1960, p. 6.

. "Joven iracundo." [Notas bibliográficas sobre El país de la cola de paja]. El País (Montevideo), 26 diciembre 1960, p.6.

[Nota bibliográfica sobre La tregua]. El País (Montevideo), 2 enero 1961.

. "Dr. Jekyll y Mr. Hyde." El País (Montevideo), 12 febrero 1962, p. 6.

. "Nuestras vulgaridades." [Nota bibliográfica sobre Inventario]. El Pais (Montevideo), 9 febrero 1964, p. 7.

5 . "Benedetti y el teatro." El Pais (Montevideo), 29 junio 1968, p.

Narradores uruguayos. Caracas: Ed. Monte Avila, 1969, pp. 201-202. [Nota bio-bibliográfica]

. "Dr. Jekyll y Mister Hyde.” En: Ruffinelli, Jorge. Comp. Mario Benedetti: variaciones críticas. Montevideo: Libros del Astillero, 1973, pp. 189-190.

Cros, Graciela. [Reseña crítica sobre Inventario 70]. Uno por Uno (Buenos Aires), No. 8, s.f.

Crow, John A. [Reseña sobre La tregua]. Saturday Review (Nueva York), 10 enero 1970 , pp. 44-45, 98.

. "La felicidad y la derrota." En: Ruffinelli, Jorge. Comp. Mario Benedetti: variaciones críticas. Montevideo: Libros del Astillero, 1973, pp. 181-182.

Curuchet, Juan Carlos. "Los montevideanos de Mario Benedetti." Cuadernos hispanoamericanos (Madrid), No. 232, abril 1969, pp. 141-148.

\section{D}

Daelli, Luciana. Poesía lírica del siglo XX: España e Hispanoamérica. [Antología en colaboración con Celina Manzoni]. Buenos Aires: Centro Editor de América Latina, 1972, pp. 111-113. 
Darino, H.O. [Nota bibliográfica sobre Quién de nosotros]. Agón (Montevideo), No. 2, julio 1954, p. 16.

Dauster, Frank. [Nota bibliográfica sobre Cuentos completos]. Books Abroad (Norman, Oklahoma), julio 1971, p. 485.

. "Cuentos completos." En: Ruffinelli, Jorge. Comp. Mario Benedetti: variaciones críticas. Montevideo: Libros del Astillero, 1973, pp. 174-175.

Delano, Luis Enrique. "Los cuentos de Benedetti." [Nota bibliográfica sobre Cuentos Completos]. Ultima Hora (Santiago de Chile], 16 septiembre 1970 , p. 4.

Delano, Poli. "Benedetti, elevación de la poesía cotidiana." Ultima hora (Santiago de Chile), 16 febrero 1962, p. 4.

de la Peña, Alfredo. "Las sorpresas bienvenidas." Acción (Montevideo), 4 mayo 1969 , p. 7.

de la Torriente, Loló. "Mario Benedetti interpreta a Darío." [Nota bibliográfica sobre Poesias, de Rubén Darío, antología y prólogo de M.B., La Habana: Casa de las Américas, 1967]. El Mundo (La Habana), 17 enero 1963.

Díaz, Jesús. "Prólogo" a Montevideanos. La Habana: Casa de las Américas, 1968.

. "La fábula del espejo." En: Ruffinelli, Jorge. Comp. Mario Benedetti: variaciones criticas. Montevideo: Libros del Astillero, 1973, pp. 124-131.

"Inventario de una moral en crisis." En: Fornet, Ambrosio. Comp. Recopilación de textos sobre Mario Benedetti. La Habana: Casa de las Américas, 1976, pp. 203-210.

Díaz Lastra, Alberto. "Entrevista con Mario Benedetti." [Reportaje]. Suplemento cultural de iSiempre! (México, D.F.), No. 223, 25 mayo 1966, pp. III y IV.

Díez, Luis Alfonso. "En la hora de los tupamaros: la antipoesía de Mario Benedetti." Artes y Letras, suplemento de El Norte de Castilla (Valladolid), 9 enero 1972.

Donoso Pareja, Miguel. "Gracias por el fuego." [Reseña de la edición mexicana ERA]. El Día (México, D.F.), 30 junio 1969, p. 12.

"La novelística latinoamericana: Uruguay." El Día (México, D.F.), 1 diciembrè: 1969. 
Dorfman, Ariel. "Edipo en Uruguay." [Nota crítica sobre Gracias por el fuego]. Ercilla (Santiago de Chile), 15 junio 1966, p. 35.

. "Un panorama mayor." En: Ruffinelli, Jorge. Comp. Mario Benedetti: variaciones críticas. Montevideo: Libros del Astillero, 1973, pp. 183-184.

E

Ehrmann, Juan. "Benedetti: dualidad superada." [Nota crítica sobre La muerte $y$ otras sorpresas]. Ercilla (Santiago de Chile), Año XXXIV, No. 1793, 29 octubre-4noviembre 1969, pp. 84-85.

Englekirk, John E. La narrativa uruguaya. [En colaboración con Margaret M. Ramos]. Berkeley y Los Angeles: University of California Press, 1967, pp. 21 y ss., pp. 121-123.

Espinosa, Mario. "El mes de los libros." [Incluye comentario sobre Quién de nosotros]. La Nación (Santiago de Chile), 11 julio 1954.

Etcheverry, José Enrique. "Una veintena y pico de narradores." [Incluye comentario sobre novelas y cuentos de M.B.]. El Plata (Montevideo), Ed. del Cincuentenario, 1964, p. 7.

Eyherabide, Gley. "Mario Benedetti con el pie en el estribo." Hechos (Montevideo), 8 enero 1966.

F

Fernández, Oscar. "Mario Benedetti: Four Stories, Four Styles." Studies in Short Fiction (Newberry, South Carolina), No. 11, 1974, pp. 283290.

Fernández Retamar, Roberto. "Benedetti entre nosotros." El Mundo (La Habana), 22 febrero 1969, p. 2.

. "Benedetti entre nosotros." Marcha (Montevideo), Vol. 30, No. 1440, 14 marzo 1969, p. 29.

. "La obra novelística de Mario Benedetti." Revista de la Universidad de La Habana (La Habana), Vol. 1, No. 195, 1972, pp. 111-121. 
. "La obra novelística de Mario Benedetti." En: Ruffinelli, Jorge. Comp. Mario Benedetti: Variaciones críticas. Montevideo: Libros del Astillero, 1973, pp. 59-73.

"La obra novelística de Mario Benedetti." En: Fornet, Ambrosio. Comp. Recopilación de textos sobre Mario Benedetti. La Habana: Casa de las Américas, 1976, pp. 101-113. "Conversación con Mario Benedetti." Cambio (México, D.F.), Vol. 2, No. 5, 1976, pp. 23-30.

Ferrandiz Alborz, F. "La temática de Mario Benedetti." [Reseña crítica sobre Montevideanos ]. Acción (Montevideo), 14 febrero 1969, p. 5.

Fierro, Enrique. "Los poetas del 45 - Mario Benedetti o el hoyporhoy." Capítulo Oriental (Montevideo), No. 32, octubre 1968, pp. 502503.

Figueira, Gastón. "Letras uruguayas: Mario Benedetti." La Semana (Guayaquil), 10 agosto 1962.

Fleitas, Alex. "En el estanquillo: La larga vida breve, de un hombre frustado." [Comentario sobre la edición cubana de La tregua]. Juventud Rebelde (La Habana), 26 febrero 1980.

. "Poesía: Hoy con Mario Benedetti." [Nota sobre Poesia, antología de la obra poética de M.B., publicada en Cuba en 1980]. Juventud Rebelde (La Habana), 28 marzo 1980.

Fonseca Moya, William. "Benedetti, la poesía y la libertad." [Entrevista]. Barricada (Managua), 27 mayo 1980.

Fontaine, Remy. "Sobre Mario Benedetti, La tregua." [Reseña sobre la edición española publicada en 1978 con un prólogo de Eduardo Nogareda]. Revista Iberoamericana (Pittsburgh), Vol. 46, No. 110111, enero-junio 1980, pp. 325-326.

Fornet, Ambrosio. Comp. Recopilación de textos sobre Mario Benedetti. [Prólogo y edición de textos]. La Habana: Casa de las Américas, 1976.

Fornaro, Milton. "El cumpleaños de un 'best-seller." [Reseña crítica sobre El cumpleaños de Juan Angel]. Suplemento dominical de El Popular (Montevideo), agosto 1971.

Foster, David William. "Una aproximación a la escritura metateatral de Ida y vuelta de.Mario-Benedetti." Hispamérica (Buenos Aires), No. 19, 1978, pp. 13-25. 
Fraire, Isabel. "De oficinista a tupamaro." [Reseña sobre El cumpleaños de Juan Angel]. ;Siempre! (México, D.F.), 12 mayo 1971, p. XIV.

“¿Novela en verso?” En: Ruffinelli, Jorge. Comp; Mario Benedetti: variaciones criticas. Montevideo: Libros del Astillero, 1973, pp. 191-192.

Franco, Jean. The Modern Culture of Latin America. Society and the Artist. Nueva York: Fredrick A. Praeger, 1967, pp. 208-209 y 214215.

La cultura de América Latina. México, D.F.: Joaquín Mortiz, 1971, pp. 209-210, 218-219, 223-224, 235-236 у 260.

. The Penguin Companion to Literature (USA and Latin America). Londres: Penguin, 1971, pp. 302-303.

"La textura de la vida." En: Ruffinelli, Jorge. Comp. Mario Benedetti: variaciones críticas. Montevideo: Libros del Astillero, 1973, p. 174.

García Hortelano, Juan. [Reportaje]. En: Tola de Habich, Fernando y Grieve, Patricia. Los españoles y el boom. Caracas: Editorial Tiempo Nuevo, 1971, pp. 154-157.

García Puertas, Mario. [Reseña crítica sobre Literatura uruguaya, siglo $X X]$ ]. Estudios (Montevideo), noviembre-diciembre 1964, p. 92.

Garzón Céspedes, Francisco. "Prólogo" Gracias por el fuego, 2da. ed. Col. Literatura Latinoamericana. La Habana: Casa de las Américas, 1976.

Gelman, Juan. "Mario Benedetti: el escritor es un trabajador como tantos." [Reportaje] Crisis (Buenos Aires), No. 19, noviembre 1974, pp. 4050 .

Gold, Arthur. "Love's gift: the courage to confide." [Reseña critica sobre The Truce, trad. al inglés de La tregua]. The New York Times Book Review (Nueva York), 19 octubre 1969, p. 55.

Gómez Jara, Francisco A. [Nota bibliográfica sobre Montevideanos]. Comunidad (México, D.F.), No. 17, febrero 1969, p. 69.

González Bermejo, Ernesto. "Con Mario Benedetti." Casa de las Américas (La Habana), Vol. 11, No. 65-66, marzo-abril 1971, pp. 148-155. 
."El caso Mario Benedetti." En: Ruffinelli, Jorge. Comp. Mario Benedetti: variaciones críticas. Montevideo: Libros del Astillero, 1973, pp. 26-41.

Gravina, Alfredo Dante. "Lo nacional en la literatura y La tregua de Mario Benedetti." El Popular (Montevideo), 27 enero 1961, pp. 27.

Guerrero Martín, José. “Acción y creación intelectual en América Latina. Mario Benedetti: 'Frente al genocidio cultural, crear cada vez más." [Entrevista]. La Vanguardia (Barcelona), 28 marzo 1980, p. 13.

Guerrero Zamora, Juan. Historia del teatro contemporáneo. Barcelona: Editorial Juan Flors, 1967, pp. 612-613.

Gutiérrez, Carlos María. "La mala conciencia de los intelectuales." Prólogo (Montevideo), No. 1, noviembre-diciembre 1968, pp. 65-80.

Guyot, Joelle. "Retrato de un 'caudillo' en Gracias por el fuego." [Trad. por Carlos de Arce]. En: Fornet, Ambrosio. Comp. Recopilación de textos sobre Mario Benedetti. La Habana: Casa de las Américas, 1976, pp. 141-158.

H. G. G. [Comentario crítico sobre El pais de la cola de paja]. México en la Cultura (México, D.F.), No. 630, 10 abril 1961, p. 2.

. [Comentario crítico sobre El cumpleaños de Juan Angel]. ¡Siempre! (México, D.F.), No. 938, 16 junio 1971, p. XIII.

Hayden, Rose Lee. An Existential Focus on Some Novels of the River Plate. East Lansing: Latin American Studies Center, Michigan State University, 1973.

Henderson, Carlos. "Un cantar de la más alta poesía." Revista de la Universidad de México (México, D.F.), Vol. 26, No. 9, mayo 1972, p. 37.

Huasi, Julio. "Mario Benedetti: literatura y lucha." Servicio Especial de la Prensa Latina (Santiago de Chile), 1971, p. 14.

"Entrevista a -Mario Benedetti." Casa de las Américas (La Habana), Vol. 12, No. 70, enero-febrero 1972, p. 181. 
Ibáñez Lonelas, J. M. "Mario Benedetti: La tregua." Madrid Cultura (Madrid), 1971.

I. G. [Reseña crítica sobre La tregua]. Correo de la Tarde (Buenos Aires), 1 agosto 1962, p. 3.

Iglesias, Heber. [Reseña crítica sobre Gracias por el fuego]. Puerto (San Juan, Puerto Rico), No. 1, octubre-noviembre 1967, pp. 108-109.

\section{$\mathbf{J}$}

Jaramillo Levi, Enrique. "Benedetti: un profesional de la narrativa breve." [Reseña crítica sobre La muerte y otras sorpresas]. Revista de la Universidad de México (México, D.F.), Vol. 25, No. 12, agosto 1970, pp. 38-40.

\section{K}

Körner, Karl-Hermann. "Zur Diskussions um die Funktion der 'Sprache' im Neuer Roman Hispano-amerikas: Metasprache bei Mario Benedetti." Romanistiches Jahrbuch (Berlín), No. 20, 1969, pp. 339-352.

."El metalenguaje en las novelas de Benedetti." En: Ruffinelli, Jorge. Comp. Mario Benedetti: variaciones críticas. [Trad. al español]. Montevideo: Libros del Astillero, 1973, pp; 83-96.

Kuehne, Alyce de. "Influencias de Pirandello y de Brecht en Mario Benedetti." Hispania (Worcester, Mass:), Vol. 51, No. 3, septiembre 1978, pp. 408-415.

Larrazábal, Libe de. [Reseña crítica sobre El cumpleaños de Juan Angel.] Siete Días (Buenos Aires), Vol. 4, 247, 7-13 febrero 1972, p. 82.

Latcham, Ricardo. "Mario Benedetti y sus montevideanos." Deslinde (Montevideo), No; 13, abril 1960, p. 6. 
"Mario Benedetti, novelista." [Reseña crítica sobre La tregua]. Deslinde (Montevideo), junio 1961, p. 14.

. "Montevideanos, por Mario Benedetti." En su: Carnet critico, ensayos. Montevideo: Alfa, 1962, pp. 141-147.

"La Tregua, por Mario Benedetti." En su: Carnet crítico, ensayos. Montevideo: Alfa, 1962, pp. 148-152.

. [Artículo crítico sobre Literatura uruguaya siglo $X X]$. La Nación (Santiago de Chile), 9 febrero 1964, p. 5.

"Situaciones amorosas." En: Ruffinelli, Jorge. Comp. Mario Benedetti: variaciones críticas. Montevideo: Libros del Astillero, 1973, p. 132.

Lavin Cerda, Hernán. "El deterioro del político profesional." [Reportaje a M.B.]. Punto Final (Santiago de Chile), No. 90, 28 octubre 1969.

. "Mario Benedetti, la fantasía y la muerte." [Crítica sobre La muerte y otras sorpresas]. Ultima Hora (Santiago de Chile), 1 noviembre 1969 , p. 4.

. "Contra el liberalismo." [Entrevista between H.L.C. y Mario Benedetti]. Casa de las Américas (La Habana), Vol. 10, No. 59, marzo-abril 1970, pp. 197-198.

Leach, Doroty Ann. [Nota bibliográfica sobre La tregua]. Herald Post (El Paso, Texas), 27 septiembre 1969, p. 4.

Leal, Luis. "Mario Benedetti." En su: Historia del cuento hispanoamericano. México: Ediciones De Andrea, 1966.

"Mario Benedetti." En su: Breve historia de la literatura hispanoamericana. Nueva York: Alfred A. Knopf, 1971, pp. 354355.

Legido, Juan Carlos. El teatro uruguayo. [Incluye comentario sobre Ida y vuelta]. Montevideo: Tauro, 1968.

Lewald, Ernest H. "The 1965 literary scene in Argentina and Uruguay." Books Abroad (Norman, Oklahoma), Spring 1966.

Lihn, Enrique. "Entrevista a Mario Benedetti, Montevideano de vocación." [En colaboración con Germán Marín]. Cormorán (Santiago de Chile), Vol. 1, No. 5, enero 1970, p. 3.

Lizardi, Francisco. [Nota bibliográfica sobre La muerte y otras sorpresas]. Caballero (México, D.F.), marzo 1969, p. 14. 
Llopis, Rogelio. [Reseña sobre Montevideanos]. Casa de las Américas (La Habana), Vol. 4, No. 24, octubre-noviembre 1964, pp. 162-164.

López Narvaez, Froylan M. "Dos magníficos: Paradiso y Benedetti." [Incluye comentario sobre La muerte y otras sorpresas]. Excélsior (México, D.F.), 10 noviembre 1968, p. t.

Loveluck, Juan. "La tregua, de Mario Benedetti." El Sur (Concepción, Chile), 9 abril 1961.

Loyola, Hernán. "Mario Benedetti." Ultima Hora (Santiago de Chile), 12 octubre 1969, p. 5.

. "Benedetti: Gracias por el fuego." Ultima Hora (Santiago de Chile), 12 julio 1970, p. 6.

Ludmer, Josefina. "Nombres femeninos como asiento del trabajo ideológico en dos novelas de Mario Benedetti" Nuevos Aires (Buenos Aires), No. 8, agosto-octubre 1972, pp. 11-18.

"Nombres femeninos como asiento del trabajo ideológico en dos novelas de Mario Benedetti (puntos de partida para un análisis crítico)." En: Ruffinelli, Jorge. Comp. Mario Benedetti: variaciones críticas. Montevideo: Libros del Astillero, 1973, pp. 97-107.

Luzi, Mario. “A Montevideo." [Reseña crítica sobre Grazie per il fuoco, trad. al italiano de Gracias por el fuego]. Il corriere de la Sera (Milán), 28 diciembre 1972.

$\mathbf{M}$

M. C. G. "Cuentos de Mario Benedetti." [Crítica sobre Cuentos completos]. Pec (Santiago de Chile), No. 374, 23 octubre 1970, p. 13.

[Magaña Esquivel, Antonio] A.M.E. “¿Novela biográfica?” [Reseña crítica sobre El cumpleaños de Juan Angel]. Tiempo (México, D.F.), Vol. 59, No. 125, 26 julio 1971, p. 3.

Mansour, Mónica. Tuya, mía, de otros: la poesía coloquial de Mario Benedetti. México, D.F.: UNAM, 1979.

Mántaras Loedel, Graciela. "Generación del 45." Prólogo (Montevideo), No. 1, noviembre-diciembre 1968, pp. 13-22.

[Marechal, Yamandú] Y.M.B. [Nota bibliográfica sobre La muerte y otras sorpresas]. Ahora (Montevideo), 8 marzo 1972. 
Marian, Eugen. "Un intérprete ideal." Magazin (Bucarest), No. 351, 27 junio 1964, p. 8.

Marques Ravelo, Bernardo. "Benedetti sin treguas." [Artículo sobre la edición cubana de La tregua]. El Caimán Barbudo (La Habana), No. 148, abril 1980, p. 22.

Marra, Nelson. [Reseña crítica sobre Gracias por el fuego]. Estudios (Montevideo), No. 26, julio-agosto 1965, pp. 126-128.

. "Poesía amorosa hispanoamericana." [Nota bibliográfica sobre Poesías de amor hispanoamericanas]. El Popular (Montevideo), 9 enero 1970.

Martí Gómez, José. "Benedetti y las vidas rotas en pedacitos." [Entrevista]. El Periódico (Barcelona), 25 marzo 1980, pp. 28-29.

Martínez, Pablo A. "Mario Benedetti en la literatura uruguaya." ; Ahora! (Santo Domingo), Vol. 8, No. 298, 1969.

Martínez, Raúl Victor. "De Benedetti: cuentos y poesías." [Artículo sobre las ediciones cubanas de La tregua, Poesía y Todos los cuentos de Mario Benedetti]. Bohemia (La Habana), 23 mayo 1980, p. 36.

Martínez Moreno, Carlos. [Artículo crítico sobre Quién de nosotros]. Marcha (Montevideo), No. 708, 12 febrero 1954, pp. 14-15.

Ida y vuelta, de Mario Benedetti." [Artículo crítico sobre el estreno teatral]. Marcha (Montevideo), 25 julio 1958, p. 17.

Montevideo en la literatura y en el arte. Montevideo: Nuestra Tierra, 1971, pp. 40 y ss.

Martini, Juan Carlos. "Mario Benedetti y los espejismos de La tregua." [Reportaje]. Confirmado (Buenos Aires), 22 agosto 1972, pp. 3435 .

Marún, Gioconda. "Análisis literario de El cumpleaños de Juan Angel, de Mario Benedetti." Texto Crítico (Veracruz), No. 6, enero-abril 1977, pp. 161-177.

Mathieu, Corina S. Contenido y técnica en los cuentos de Mario Benedetti. [Tesis]. Stanford: Stanford University, 1973.

"Aspectos del mundo burgués de Mario Benedetti." En: Kraft, Walter C., Ed. "Proceedings: Pacific Nort west Conference of Foreign Languages, 25th Annual Meeting, abril 19-20 1974, Eastern Washington State College." Vol. 25, part 1: Literature and Linguistics. Corvallis: Oregon State University, pp. 173-176. 
. "Quién de nosotros: un libro y una narrativa." En: Ruffinelli, Jorge. Comp. Mario Benedetti: variaciones críticas. Montevideo: Libros del Astillero, 1973, pp. 42-48.

Mediza, Alberto. "Poetas comunicantes." El Popular (Montevideo), 15 diciembre 1972.

Meehan, Thomas C. "Mario Benedetti: La tregua." Books Abroad (Norman, Oklahoma), Vol. 45, No; 1, 1971, pp. 77-78.

Mejía Duque, Jaime. "Ensayo y compromiso en Benedetti." La Palabra y el Hombre: revista de la Universidad Veracruzana (Veracruz), No. 13 , pp. 21-27.

Meléndez, Concha. "El subsuelo irracional." En: Ruffinelli, Jorge. Comp. Mario Benedetti: variaciones críticas. Montevideo: Libros del Astillero, 1973, p. 173.

Mercier, Lucien. "La palabra bajada del Olimpo." Crisis (Buenos Aires), No. 19 , noviembre 1974 , pp. $46-47$.

. "La palabra bajada del Olimpo." En: Fornet, Ambrosio. Comp. Recopilación de textos sobre Mario Benedetti. La Habana: Casa de las Américas, 1976, pp. 239-246.

[Milla, Benito] B.M. "Resurge la literatura uruguaya." Acción (Montevideo), 31 octubre 1961, p. 5.

"Mario Benedetti entre viaje y viaje." Acción (Montevideo), 8 abril 1962, p. 5.

Mir, Zainola. "Montevideanos, de Mario Benedetti." [Artículo crítico]. Taller Literario (Santiago de Cuba), No. 17, julio 1968, pp. 18-19.

Moreira Rojas, Alberto A. [Reseña crítica sobre Poemas de la oficina]. Comentario (Buenos Aires), Vol. 3, No. 12, julio- septiembre 1956, pp. 106-107.

Mourigan, Carlos Alberto A. "Nuestra orientación crítica." [Artículo crítico sobre Literatura uruguaya siglo XX]. Acción (Montevideo), 26 julio 1964, p. 7.

Muñoz Lagos, Marino. [Reseña crítica sobre Cuentos completos]. El Magallanes (Chile), 24 octubre 1970, p. 3.

N.A.C. [Nota bibliográfica sobre Contra los puentes levadizos]. La Prensa (Buenos Aires), 16 agosto 1969. 
Niemczyk, Mike. "Cynical Hero." [Reseña crítica sobre La tregua]. American Statesman (Austin, Texas), 14 diciembre 1969, p. T 36.

Nogareda, Eduardo. "Prólogo y bibliografía selecta." En: La tregua. Madrid: Cátedra, 1978.

[Novoa, Felipe] F.N. [Reseña crítica del libro Sobre artes y oficios]. El Popular (Montevideo), 23 octubre 1968.

Oberhelman, H.D. [Reseña crítica sobre Cuentos completos]. Hispania (Worcester, Mass.), Vol. 54, diciembre 1971, p. 976.

Obiol, Salvador. "Tres nombres en la poesía uruguaya: Vilariño, Cunha, Benedetti." Hoy en la cultura (Buenos Aires), No. 14, junio 1964, p. 12.

Onetti, Jorge. "Benedetti una experiencia cubana." [Entrevista]. Marcha (Montevideo), 23 mayo 1963.

Orozco, Arturo. "El último libro de Benedetti." [Reseña crítica sobre $L a$ muerte y otras sorpresas]. El Día (México, D.F.), 28 abril 1969, p. 8.

Osnajanski, Norma. "Benedetti, ternura sin piedad." [Artículo crítico sobre Inventario 67 y $A$ ras de sueño]. Uno por Uno (Buenos Aires), No. 1, mayo 1969.

"Mario Benedetti. De opciones y prioridades." [Reportaje en colaboración con Sergio Sinay sobre Mario Benedetti]. Uno por Uno (Buenos Aires), Vol. 2, No. 11, junio 1971, pp. 18-20.

Ossa, Carlos. “¿Para qué escriben los escritores?” Hechos Mundiales (Santiago de Chile), No. 61, enero 1961, p. 55.

Otero, José Manuel. “Montevideanos es un buen libro." Verde Olivo (La Habana), 19 mayo 1968, p. 19.

Oviedo, José Miguel. "La tregua de Mario Benedetti: un diario de un jubilado de la vida." Dominical, suplemento semanal de $E l$ Comercio (Lima), 23 octubre 1966, p. 17.

. "Benedetti, un dominio colonizado por la poesía." [Reseña crítica sobre Inventario 67]. Amarú (Lima), No. 4, octubrediciembre 1967, pp. 78-81. 
" "El uruguayo en su callejón sin salida." Dominical, suplemento semanal de El Comercio (Lima), 10 octubre 1967, p. 22.

. "Benedetti, crítico practicante." El Comercio (Lima), 3 noviembre 1968, p. 29.

"6 preguntas a Mario Benedetti." [Reportaje]. El Comercio (Lima), 12 octubre 1969, pp. 36-37.

"Un dominio colonizado por la poesía." En: Ruffinelli, Jorge. Comp. Mario Benedetti: variaciones críticas. Montevideo: Libros del Astillero, 1973, pp. 147-158.

Pacheco, Cristina. "Con Mario Benedetti: Un grande de las letras de América." [Entrevista]. iSiempre! (México, D.F.), No 1325, 15 septiembre, 1978, pp. 32-34, 70.

Paganini, Alberto. Los críticos del 45. Capítulo Oriental: 35. Montevideo: Centro Editor de América Latina, 1969.

Los cuentistas del 45. [Incluye notas críticas sobre Mario Benedetti]. Capítulo Oriental: 34. Montevideo: Centro Editor de América Latina, 1968.

Paternain, Alejandro. "En el territorio de los líricos." El Plata (Montevideo), 1964, pp. 8-11.

Peredo, Roberto. "Mario Benedetti: Gracias por el fuego." [Artículo crítico]. Comunidad (México, D.F.), No. 30, 1971, pp. 237-238.

Pérez Pintos, Diegos. "Benedetti inadaptado." [Artículo crítico sobre Poemas de oficina]. Ceipa (Montevideo), No. 1, enero 1957, pp. 65-68.

Pérez Valdez, Trinidad. "Benedetti: conciencia y testimonio de su experiencia cubana." [Artículo sobre Cuaderno cubano]. Casa de las Américas (La Habana), Vol. 10, No. 59, marzo-abril 1970, pp. 180-181.

Peri Rossi, Cristina. "Poesía de amor hispanoamericana." [Reseña crítica sobre Poemas de amor hispanoamericanos]. Marcha (Montevideo), 7 noviembre 1969, p. 30.

"El compromiso trágico del cumpleaños de Juan." El Eco (Montevideo), No. 8349, 1 septiembre 1971, p. 50. 
. "Respuestazo." En: Ruffinelli, Jorge. Comp. Mario Benedetti: variaciones criticas. Montevideo: Libros del Astillero, 1973, p. 191.

Piazza, Luis Guillermo. "Poemas uruguayos." [Comentario crítico sobre Inventario]. Excélsior (México, D.F.), 20 diciembre 1964, p. 4.

Porzio, Domenico. [Reseña sobre Grazie per il fuoco]. Panorama (Milán), 27 julio 1972, p. 10.

Le piú belle novelle di tutti i paesi (1963). [Incluye "Il resto é selva"]. Milán: Aldo Martello Editore, 1973.

Prada Orpeza, Renato. "Mario Benedetti: El recurso del supremo patriarca." [Reseña]. Texto Crítico (Vera Cruz), No. 14, 1979, pp. 211-215.

Prasel, Salvador. "Un novelista del humor negro." [Nota bibliográfica sobre Gracias por el fuego]. Imagen (Caracas), No. 21, marzo 1968, p. 6.

Prego Gadea, Omar. "Benedetti cuentista." [Nota bibliográfica sobre $E l$ último viaje y otros cuentos.] Marcha (Montevideo), 1951.

. "El libro de la semana." [Reseña crítica sobre la 3ra. edición de Montevideanos]. El Diario (Montevideo), 19 julio 1964.

. "Un Uruguay oculto." [Reseña crítica sobre Gracias por el fuego]. El Diario (Montevideo), 20 junio 1965.

"Apertura al mundo." [Reseña crítica sobre la antología Narradores rumanos]. El Diario (Montevideo), 22 agosto 1965.

Pring-Mill, R. "Letras de emergencia." Times Literary Supplement (Londres), 6 agosto 1976, p. 994.

Privitera, Rodolfo. "Gracias por el fuego." [Reseña]. Nueva narrativa hispanoamericana (Nueva York), Vol. 1, No. 1, 1971, pp. 164-165.

Promis Ojeda, José. "Mario Benedetti: Gracias por el fuego." [Reseña]. Anales de la Universidad de Chile (Santiago de Chile), Vol. 124, No. 139, julio-septiembre 1969, pp. 252-257.

Puentes, Santiago. [Reseña sobre Montevideanos]. Nuestros Hijos (Buenos Aires), No. 161, octubre 1968, p. 17.

. "Doble ración." [Reseña de Quién de nosotros y La muerte y otras sorpresas]. Nuestros Hijos (Buenos Aires), No. 165, marzoabril 1969, p. 11.

Pujol, Felix. "Mario Benedetti, entre la literatura y la política." [Entrevista]. La Vanguardia (Barcelona), 22 marzo 1980, p. 23. 
Pujol, José Luis. [Artículo crítico sobre El escritor latinoamericano y la revolución posible]. Casa de las Américas (La Habana), No. 87, noviembre-diciembre 1974, pp. 127-129.

Rabassa, G. [Reseña sobre Marcel Proust y otros ensayos]. Revista Hispánica Moderna (Nueva York), enero 1953, p. 107.

Rama, Angel. [Reseña crítica sobre estreno de Ida y vuelta]. Acción (Montevideo), 18 julio 1958.

."El escritor y su país." [Artículo crítico sobre El país de la cola de paja]. Marcha (Montevideo), 16 diciembre 1960.

. "La madurez del oficio de un narrador." [Reseña sobre $\mathbf{L a}$ tregua]. Marcha (Montevideo), Vol. 23, No. 1123, 20 abril 1961, p. 5.

. "Del horizonte de uno al horizonte de todos." [Artículo crítico sobre Inventario]. Marcha (Montevideo), 16 julio 1965.

. "Benedetti, ida y vuelta." [Reportaje]. Marcha (Montevideo), Vol. 27, No. 1359, 30 junio 1967, p. 30.

"180 años de literatura." Montevideo: Editorial Reunidos y Arca, Serie Enciclopedia Uruguaya, fascículo No. 2, 1968, pp. 3839.

La conciencia crítica. Montevideo: Editorial Reunidos y Arca, Serie Enciclopedia Uruguaya, fascículo No. 56, 1968, pp. 112 y ss. . "La generación crítica (1939-1969)." [4a. parte del volumen colectivo de Uruguay Hoy]. Buenos Aires: Siglo XXI, 1971, pp. 394 y ss.

. "La generación crítica (1939-1969)." I. Panoramas. Montevideo: Arca, 1972.

Real de Azúa, Carlos. [Reseña crítica sobre Esta mañana]. Escritura (Montevideo), 1950, No. 9, pp. 135-136.

. "Legatarios de una demolición." Marcha (Montevideo), No. 1188, 27 diciembre 1963.

. El Uruguay visto por los uruguayos. [Incluye "El voto que el alma denuncia"]. Montevideo, Buenos Aires: Centro Editor de 
América Latina, Biblioteca Uruguaya Fundamental, Vol. 26, 1968, pp. 161-163.

Reboredo, Aída. "El escritor no debe hacerle concesiones ni al lector ni a la crítica debe ser fiel a sí mismo: Mario Benedetti." [Entrevista]. Uno más Uno (México, D.F.), 8 mayo 1980, p. 16.

Rein, Mercedes. “¿Quién es, quién era Benedetti?” [Artículo crítico sobre Contra los puentes levadizos]. Marcha (Montevideo), Vol. 29, No. 1362, 22 julio 1967, p. 31.

. "La poesía de Benedetti: balance provisorio." En: Fornet, Ambrosio. Comp. Recopilación de textos sobre Mario Benedetti. La Habana: Casa de las Américas, 1976, pp. 225-231.

Ricapito, Joseph V. "Sobre La tregua de Mario Benedetti." Cuadernos hispanoamericanos (Madrid), No. 331, 1978, pp. 143-151.

R.F.C. [Nota bibliográfica sobre Literatura uruguaya siglo XX.] La Prensa (Buenos Aires), 13 septiembre 1964.

Rodán, Eleuterio M. "Poeta en la oficina." [Reseña crítica sobre Poemas de la oficina]. El Nacional (Buenos Aires), 20 agosto 1958.

Rodríguez, Oscar. "Benedetti y Camus." En: Ruffinelli, Jorge. Comp. Mario Benedetti: variaciones críticas. Montevideo: Libros del Astillero, 1973, p. 180.

. [Reseña crítica sobre La tregua]. Diorama de la Cultura. Suplemento dominical de Excélsior (México, D.F.), 5 octubre 1969, p. 3.

Rodríguez Monegal, Emir. "Las ficciones de un testigo implicado: Mario Benedetti." En su: Narradores de esta América. Montevideo: Alfa, 1961, pp. 209-255.

. "Prólogo" a Montevideanos. Montevideo: Alfa, 1961, 2a. ed., pp. 9-17.

. "Un montevideano y sus Montevideanos." En su: Narradores de esta América. Montevideo: Alfa, 1961, pp. 189-195.

. "Sobre un testigo implicado." Temas (Montevideo), No. 3, septiembre-octubre 1965, pp. 17-21.

Literatura uruguaya del medio siglo. Montevideo: Alfa, 1966, pp. 86 y ss., $163-165,293-312,340-351,379$ y ss. 
"Los nuevos novelistas." En: Congreso Internacional de Literatura Iberoamericana 13 Caracas; 1968. La novela iberoamericana contemporánea. Caracas: n.p., 1968, pp. 33-42.

. "Las ficciones de un testigo implicado: Mario Benedetti." En: Ruffinelli, Jorge. Comp. Mario Benedetti: variaciones críticas. Montevideo: Libros del Astillero, 1973, pp. 49-58.

Roggiano, Alfredo A. "Mario Benedetti." [Comentario crítico]. En su: En este aire de América. México: Ed. Cultura, 1966, pp. 213-214.

Romero, Gregorio. "Poemas de la oficina." [Reseña crítica]. La Comuna (Lomas de Zamora, Argentina), 13 agosto 1958.

[Ruegger, Gustavo Adolfo.] G.A.R. "Damocles hace teatro." [Reseña crítica sobre estreno de Ida y vuelta]. El País (Montevideo), 18 julio 1958.

Ruffinelli, Jorge. "Explorando caminos." [Artículo crítico sobre La muerte y otras sorpresas]. Marcha (Montevideo), 19 septiembre 1969, p. 5. . "Prólogo" a Cuentos completos. Santiago de Chile: Editorial Universitaria, 1970, pp. 9-17.

Presentación del disco Cuentos, Montevideo, Tacuabé, 1972.

"El cuento como afirmación y búsqueda." En su: Mario Benedetti: variaciones criticas. Montevideo: Libros del Astillero, 1973, pp. 108-123.

Comp. Mario Benedetti: variaciones críticas. Montevideo: Libros del Astillero, 1973.

"El cuento como afirmación y búsqueda." En: Fornet, Ambrosio. Comp. Recopilación de textos sobre Mario Benedetti. La Habana: Casa de las Américas, 1976, pp. 189-202.

"La trinchera permanente." En su: Palabras en orden. [Entrevista con M. Benedetti]. Buenos Aires: Crisis, 1974, pp. 147170.

."La trinchera permanente." [Entrevista]. En: Fornet, Ambrosio. Comp. Recopilación de textos sobre Mario Benedetti. La Habana: Casa de las Américas, 1976, pp. 25-48. . Crítica en "Marcha". México, D.F.: Premiá, 1979.

Ruiz, Carlos Enrique. "Mario Benedetti o el ejercicio de la literatura para no envejecer de rencor o descreimiento." Revista Aleph (Manzanales), No. 30, 1979, pp. 43-37. 
Ruiz, Hugo. "Mario Benedetti, un escritor lúcido." [Artículo crítico sobre Letras del continente mestizo]. Encuentro Liberal (Bogotá), No. 55,6 julio 1968.

\section{S}

Sachs, Silvia. "3 Books Mirror Modern Life." [Incluye comentario sobre La tregua]. Pittsburgh Press (Pittsburgh), 21 septiembre 1969, p. 12.

Salazar Bondy, Sebastián. "Rodó visto por Benedetti: sin nada en común." [Reseña sobre Genio y figura de José E. Rodó]. Hechos (Montevideo), 23 julio 1967.

. "Liberación poética." En: Ruffinelli, Jorge. Comp. Mario Benedetti: variaciones críticas. Montevideo: Libros del Astillero, 1973, pp. 187-189.

Sanguinetti, Julio María. [Nota bibliográfica sobre La tregua]. Acción (Montevideo), 1961, p. 7.

Santalna, Joaquín G. "Entrevista con Mario Benedetti." Plural (México, D.F.), No. 61, 1976, pp. 64-66.

Saravia, Cora. [Reseña crítica sobre estreno de Ida y vuelta]. El Plata (Montevideo), 19 julio 1958.

Schiff, Pearl. "Promoting with Ring of Reality." [Nota bibliografica sobre La tregua]. Morning Globe (Boston, Mass.), 9 octubre 1969, p. 67.

[Schkolnik, Pablo] P.S. "El país de la cola de paja: un libro sobre el Uruguay actual." Acción (Mercedes), 28 febrero 1961, p. 5.

Scoseria, Cyro. "El teatro en el Uruguay." [Incluye referencia y comentario sobre Ida y vuelta]. Revista Nacional (Montevideo), No. 312-214, julio-diciembre 1962, p. 208.

Seiguerman, Osvaldo. "El amor a cal y canto." Análisis (Buenos Aires), No. 568, 4-10 febrero 1972, pp. 42-43.

"El amor a cal y canto." En: Fornet, Ambrosio. Comp. Recopilación de textos sobre Mario Benedetti. La Habana: Casa de las Américas, 1976, pp. 211-214.

Serrano, Pío E. "Montevideanos, épica de lo cotidiano." La Gaceta de Cuba (La Habana), abril-mayo 1968, p. 12. 
Shaw, Fred. "Junk vanishes, if you don't indulge in it." [Incluye comentario sobre La tregua]. Herald (Miami, Florida), 19 octubre 1969.

Silva, Raúl Hernán. [Reseña crítica sobre La tregua]. Boletín del Instituto de Literatura Chilena (Santiago de Chile), Vol. 1, No. 1, septiembre 1961, pp. 12-13.

Skármeta, Antonio. [Reportaje]. "El feliz cumpleaños de Mario Benedetti." Ahora (Santiago de Chile), Vol. 1, No. 24, 28 septiembre 1971, pp. 47-49.

Solórzano, Carlos. "La novela y el teatro hispanoamericano." Idea (Lima), No. 25-26, 1969.

Sorrentino, Fernando. "Mario Benedetti." En: 30 cuentos hispanoamericanos siglo $X X$ (1875-1975). Buenos Aires: Plus Ultra, 1967, p. 267.

[Sosa, Jesualdo] J. "Benedetti, humor acre y melancólico." [Reseña crítica sobre Montevideanos]. El Popular (Montevideo) 6 marzo 1960.

Spitaleri, Mario. "Gracias por el fuego: estudio de variables temáticas." Chasqui: revista de literatura hispanoamericana (Madison) Vol. 2, No. 1, 1972, pp. 31-44.

Stevenson, José. "Desfile de la clase media." [Artículo crítico sobre Cuentos completos]. Visión (Nueva York), 12 febrero 1973.

Stimson, Fredericks. [Reseña crítica sobre Montevideanos]. Books Abroad (Norman, Oklahoma), abril 1969, pp. 232-233.

Subero, Efraín. "La novela del hombre concreto: Carpentier, Sábato, Benedetti." Revista Nacional de la Cultura (Caracas), Vol. XXXII, No. 202, 1972, pp. 30-34.

Tola de Habich, Fernando. "Con sencillez." [Reseña crítica sobre $L a$ muerte y otras sorpresas]. La Prensa (Lima), 28 diciembre 1969, p. 36.

Tola de Habich, Fernando y Grieve, Patricia. Los españoles y el boom. Caracas: Tiempo Nuevo, 1971, pp. 54, 154, 158.

Torres Fierro, Danubio. "El crítico y el humorista." [Artículo crítico sobre El país de la cola de paja y Mejor es meneallo]. Acción (Montevideo), 5 noviembre 1968, p. 6. 
"Los humoristas - el humorismo y la crónica." Capitulo Oriental (Montevideo), No. 30, 1968, pp. 470-471.

Trajtenberg, Mario. "El narrador como crítico." [Artículo crítico sobre Letras del continente mestizo y Sobre artes y oficios]. Marcha (Montevideo), 27 septiembre 1968, p. 29.

."E1 narrador como crítico." En: Ruffinelli, Jorge. Comp. Mario Benedetti: variaciones críticas. Montevideo: Libros del Astillero, 1973, pp. 166-170.

T.S. "El éxito le acompaña." [Reseña crítica sobre Quién de nosotros]. El Día (Montevideo), 2 diciembre 1962, p. 195.

Ulanovsky, Carlos. "Hoy se verá el tercer capítulo de La tregua de Benedetti: es verdadero modelo de la llamada TV cultural." [Comentario crítico sobre teatro televisado, La tregua, en ciclo de "Grandes novelas", Canal 7 de Buenos Aires]. La Opinión (Buenos Aires), 20 julio 1972, p. 32.

Valente, Ignacio. [Reseña crítica sobre La tregua]. El Mercurio (Santiago de Chile), 7 marzo 1971, p. 3.

Vallejos, Roque. [Reseña crítica sobre Montevideanos]. Alcor (Asunción), julio-agosto 1963, p. 11.

Valverde, José María. "Verso versus prosa: dos casos en Hispanoamérica." Revista Canadiense de Estudios Hispánicos (Toronto), Vol. 1, No. 1, otoño 1976, pp. 101-107.

Vargas Llosa, Mario. "Diálogo con Mario Benedetti." Expresso (Roma), 11 abril 1966, p. 11.

Vázquez, Oscar. "Benedetti, el profesor muy sencillo." [Reportaje]. Ultima Hora (Santiago de Chile), 21 noviembre 1971, p. 21.

Veliova, Iglika Tzekova. Mario Benedetti: su obra narrativa. [Tesis]. La Habana: Universidad de La Habana, 1969. 
Verdovoye, Paul. "Mario Benedetti." [Nota bío-bibliográfica y tres fragmentos de Gracias por el fuego ]. En su: Antología de la narrativa hispanoamericana: 1940-1970. Madrid: Gredos, 1979, pp. 155-166.

[Villafañe, J.E.] J.E.V. [Nota bibliográfica sobre La tregua]. La Mañana (Montevideo), enero 1961.

Villordo, O.H. "Poemas de la oficina, por Mario Benedetti." Ficción (Buenos Aires), noviembre-diciembre 1958, pp. 77-78.

Visca, Arturo Sergio. "Pesimismo." En: Ruffinelli, Jorge. Comp. Mario Benedetti: variaciones críticas. Montevideo: Libros del Astillero, 1973, p. 178.

Vitureira, Cipriano S. [Artículo crítico sobre Inventario]. Estudios (Montevideo), No. 29, mayo-junio 1964, pp. 108-111.

\section{W}

Wong, Oscar. "Mario Benedetti: Poemas de otros." [Reseña]. Plural (México, D.F.), Vol. 6, No. 83, agosto 1978, pp. 67-68.

Yacowski, Rubén. "Noción de ciertas realidades." [Artículo crítico sobre Inventario]. El Popular (Montevideo), 20 marzo 1964, p. 11.

Yáñez, Rubén. El teatro actual. [Incluye comentarios y referencias sobre Ida y vuelta]. Montevideo: Centro Editor de América Latina, Serie Capítulo Oriental, fascículo No. 31, 1968.

. "La dramaturgia uruguaya de los últimos 25 años." El Gallo Ilustrado (México, D.F.), No. 509, 26 marzo 1972, p. 14.

Zambrano, Oscar. "Lo real maravilloso de América española." Hechos Mundiales (Santiago de Chile), a.v., No. 61, enero 1971, pp. 42, 43, 46. [Incluye comentarios sobre M. Benedetti y notas bibliográficas sobre La tregua y El cumpleaños de Juan Angel]. 
Zeitz, Eileen M. "Los personajes de Benedetti: en busca de identidad y existencia." Cuadernos hispanoamericanos (Madrid), No. 297, marzo 1975, pp. 635-644.

Mario Benedetti, novelista uruguayo: crítica, crisis y acción. [Tesis]. Champaign-Urbana: Universidad de Illinois, 1978.

[Reseña sobre Con y sin nostalgia]. Hispamérica (Buenos Aires). [En vía de publicación]

. "Entrevista a Mario Benedetti". Hispania (Worcester, Mass.). Vol. 63, mayo 1980, pp. 417-419.

Zokner, Cecilia. "E1 recurso del supremo patriarca/Mario Benedetti." [Nota bibliográfica]. Leia Livros (São Paulo, Brasil), octubre 1979.

Zum Felde, Alberto. Indice critico de la literatura hispanoamericana. México, D.F.: Editorial Guarania, Vol. 2, 1959, pp. 498-501.

. "Benedetti experimentalista." En: Ruffinelli, Jorge. Comp. Mario Benedetti: variaciones criticas. Montevideo: Libros del Astillero, 1973, pp. 172-173. 